\title{
Uniformly convergent additive schemes for 2D singularly perturbed parabolic systems of reaction-diffusion type
}

\author{
C. Clavero • J.L. Gracia
}

Received: date / Accepted: date

\begin{abstract}
In this work we consider parabolic 2D singularly perturbed systems of reaction-diffusion type on a rectangle, in the simplest case that the diffusion parameter is the same for all equations of the system. The solution is approximated on a Shishkin mesh with two splitting or additive methods in time and standard central differences in space. It is proved that they are firstorder in time and almost second-order in space uniformly convergent schemes. The additive schemes decouple the components of the vector solution at each time level of the discretization which makes the computation more efficient. Moreover, a multigrid algorithm is used to solve the resulting linear systems. Numerical results for some test problems are showed, which illustrate the theoretical results and the efficiency of the splitting and multigrid techniques.
\end{abstract}

Keywords parabolic 2D coupled systems · reaction-diffusion · additive schemes · Shishkin meshes · uniform convergence $\cdot$ multigrid methods

Mathematics Subject Classification (2000) MSC 65M065 • 65N06 • $65 \mathrm{~N} 12$

\section{Introduction}

In this work we analyze the numerical resolution of two dimensional parabolic singularly perturbed coupled reaction-diffusion systems of type

$$
\left\{\begin{array}{l}
\mathcal{L}_{\varepsilon} \mathbf{u} \equiv \frac{\partial \mathbf{u}}{\partial t}(\mathbf{x}, t)+\mathcal{L}_{\mathbf{x}, \varepsilon} \mathbf{u}(\mathbf{x}, t)=\mathbf{f}(\mathbf{x}, t),(\mathbf{x}, t) \in Q=\Omega \times(0, T] \\
\mathbf{u}(\mathbf{x}, t)=\mathbf{0}, \mathbf{x} \in \partial \Omega, t \in(0, T], \mathbf{u}(\mathbf{x}, 0)=\mathbf{0}, \mathbf{x} \in \bar{\Omega}
\end{array}\right.
$$

C. Clavero

Department of Applied Mathematics and IUMA, University of Zaragoza, Zaragoza, Spain E-mail: clavero@unizar.es

J.L. Gracia

Department of Applied Mathematics and IUMA, University of Zaragoza, Zaragoza, Spain E-mail: jlgracia@unizar.es 
where $\Omega=(0,1)^{2}$ and the spatial differential operator $\mathcal{L}_{\mathbf{x}, \varepsilon}$ is defined as

$$
\mathcal{L}_{\mathbf{x}, \varepsilon} \mathbf{u} \equiv-\mathcal{D} \Delta \mathbf{u}+\mathcal{A} \mathbf{u},
$$

with $\mathcal{D}=\operatorname{diag}\left(\varepsilon^{2}, \ldots, \varepsilon^{2}\right)$ a diagonal matrix of order $\ell \times \ell$ and $\mathcal{A}(\mathbf{x}, t)=$ $\left(a_{i j}(\mathbf{x}, t)\right), i, j=1,2, \ldots, \ell$. We assume that the diffusion parameter $\varepsilon, 0<$ $\varepsilon \leq 1$, can be sufficiently small, that the reaction matrix $\mathcal{A}$ satisfies

$$
\begin{aligned}
& \sum_{j=1}^{\ell} a_{i j} \geq \alpha^{2}>0, i=1,2, \ldots, \ell, \text { with } \alpha>0, \\
& a_{i i}>\beta>0, i=1,2, \ldots, \ell, \\
& a_{i j} \leq 0, \quad \text { if } \quad i, j=1,2, \ldots, \ell, i \neq j,
\end{aligned}
$$

for $(\mathbf{x}, t) \in \bar{Q}$, and then $\mathcal{A}$ is an $M$-matrix. Observe that assumptions (3) and (4) are not restrictions as it can be considered as the transformation $\mathbf{v}(\mathbf{x}, t)=$ $\mathbf{u}(\mathbf{x}, t) e^{-\mu t}$ with $\mu>0$ sufficiently large. In addition,we assume that the righthand side of the differential equation, $\mathbf{f}(\mathbf{x}, t)=\left(f_{1}(\mathbf{x}, t), f_{2}(\mathbf{x}, t), \ldots, f_{\ell}(\mathbf{x}, t)\right)^{T}$, and the reaction matrix $\mathcal{A}$ are sufficiently smooth functions, which satisfy sufficient compatibility conditions in order to guarantee that the exact solution $\mathbf{u} \in C^{4,2}(\bar{Q})$. We refer to [22, Section 3] and [24, Section 3] for a detailed discussion.

There are many works (see for instance $[3,10,14,16]$ and references therein), where the numerical approximation of singularly perturbed elliptic or parabolic 1D coupled systems of reaction-diffusion type, is considered. In those papers, the time variable is discretized by the backward Euler method, on a uniform mesh, and the spatial variable by the classical central finite difference scheme, defined on a piecewise uniform mesh of Shishkin type, proving the uniform convergence, with respect to the diffusion parameters, of the fully discrete scheme, i.e., methods which give reliable solutions on meshes having a number of grid points which is independent of the value of $\varepsilon$. To obtain the numerical approximation, at each time level of the discretization, with those methods, it is necessary to solve a linear system which requires a high computational cost, due to the fact that the components of the discrete vector solution are coupled.

In $[12,13,21]$ the case of $2 \mathrm{D}$ elliptic singularly perturbed systems were analyzed; from those papers, it follows that parabolic boundary layers, of width $\mathcal{O}(\varepsilon)$, appear at the boundary $\partial \Omega$ of the spatial domain. In [22,24] $2 \mathrm{D}$ parabolic singularly perturbed systems with two equations, also of reaction-diffusion type, are considered; in these works it is given the asymptotic behavior of the exact solution, showing again the presence of parabolic layers at the boundary of the spatial domain, and it is proved the uniform convergence of a classical method defined on a Shishkin mesh. In this paper, we show that the same behavior occurs for the 2D parabolic problem (1) with an arbitrary number of equations.

Up to our knowledge, uniformly convergent schemes that approximate efficiently the solution of problem (1) with a arbitrary number of equations, have 
not been examined previously in the literature. In this paper a finite difference scheme defined on a Shishkin mesh is proposed and the analysis of the uniform convergence is given in detail. The Laplacian operator is approximated by using the standard central differences and a splitting or additive scheme [26] is used for the time discretization, because of one of our main aims in this paper is to approximate the solution of problem (1) with a low computational cost. From a numerical point of view, it is very convenient to construct numerical algorithms which decouple the approximation of the components. In [1] an additive scheme is used to discretize in time a 1D singularly perturbed parabolic system of reaction-diffusion equations; then, the computational cost is reduced considerably. Here, we are interested in extending this approach to the case of the $2 \mathrm{D}$ problem (1).

Even with a method which decouples the components, at each time level the numerical algorithm has to solve a pentadiagonal linear system for each unknown. In order to solve them efficiently, we use a multigrid method [25], which is one of the more efficient methods to solve linear systems associated to the discretization of partial differential equations. Nevertheless, multigrid methods with standard components are not convergent when the numerical schemes are defined on meshes of Shishkin type. Similar to [7] and [8], the restriction operator from fine-to-coarse meshes is appropriately defined in order that the multigrid algorithm efficiently performs in practice.

The paper is organized as follows. In Section 2 we give the asymptotic behavior of the exact solution $\mathbf{u}$ of (1) with respect to $\varepsilon$ and appropriate bounds of its derivatives. In Section 3, we construct two fully discrete schemes, which combines an additive scheme, on the basis of Jacobi or Gauss-Seidel iteration, to discretize in time and the central finite difference scheme to discretize in space. The time discretization is defined on a uniform mesh and the spatial discretization is defined on a nonuniform special mesh of Shishkin type. We prove that the fully discrete schemes, which combine both types of discretizations, are uniformly convergent methods of first-order in time and almost secondorder in space. In Section 4 we describe how the multigrid technique can be implemented to solve the linear systems which appear at each time level of the discretization. Apart from a specially designed restriction operator, the other components of the multigrid algorithm are standard. Finally, in Section 5 , we show the numerical results obtained for different test problems, which corroborate in practice the theoretical results and the advantage to use the splitting and multigrid techniques.

We denote by $\mathbf{v} \leq \mathbf{w}$ if $v_{i} \leq w_{i}, i=1,2, \ldots, \ell,|\mathbf{v}|=\left(\left|v_{1}\right|,\left|v_{2}\right|, \ldots,\left|v_{\ell}\right|\right)^{T}$ and $\|\mathbf{f}\|_{D}=\max \left\{\left\|f_{1}\right\|_{D},\left\|f_{2}\right\|_{D}, \ldots,\left\|f_{\ell}\right\|_{D}\right\}$, where $\|\cdot\|_{D}$ is the maximum norm on the domain $D$. We will omit $D$ where it is clear in the context. In order to simplify the notation, we consider the following subsets

$$
\begin{aligned}
& \Gamma_{1}=\{(x, 0), 0 \leq x \leq 1\}, \Gamma_{2}=\{(0, y), 0 \leq y \leq 1\} \\
& \Gamma_{3}=\{(x, 1), 0 \leq x \leq 1\}, \Gamma_{4}=\{(1, y), 0 \leq y \leq 1\}
\end{aligned}
$$


which are the edges of $\partial \Omega$. In some places it is used the set $\Gamma_{5}=\Gamma_{1}$ for the same purpose. The four corners of the spatial domain are denoted by

$$
c_{1}=\Gamma_{1} \cap \Gamma_{2}, c_{2}=\Gamma_{2} \cap \Gamma_{3}, c_{3}=\Gamma_{3} \cap \Gamma_{4}, c_{4}=\Gamma_{4} \cap \Gamma_{1},
$$

and we denote by $\Gamma=\{(\mathbf{x}, 0), x \in \Omega\} \cup\{(\mathbf{x}, t), \mathbf{x} \in \partial \Omega, t \in[0, T]\}$.

Henceforth, $C$ denotes any positive constant independent of the diffusion parameter $\varepsilon$ and the discretization parameters $N$ and $M$, which can take different values at different places.

\section{The continuous problem: asymptotic behavior}

In this section we give appropriate estimates of the derivatives of the solution $\mathbf{u}$ of problem (1) showing its asymptotic behavior. These estimates are used to construct and analyze the uniform convergence of the forthcoming finite difference scheme.

In the case that the system has only two equations, bounds on the derivatives of the solution were established in $[22,24]$ on the basis of the decomposition solution technique. An appropriate decomposition of the solution is given in these papers; each component of this decomposition is defined as the solution of a differential problem with appropriate boundary and initial conditions. The regularity of each component is guaranteed using smooth extensions of the domain and then estimates of their derivatives are obtained using appropriate barrier functions. The maximum principle [19] is necessary in this analysis.

Although the maximum principle can be proved using a standard argument and the hypothesis on the reaction matrix $\mathcal{A}$, we follow the proof given in $[13$, Section II] (cf. [17]), which is based on an iteration process. In this process a sequence of uncoupled problems is defined whose solution converges to the solution of the continuous problem. This iteration process will inspire the additive schemes proposed in this paper.

In the case of the system of parabolic equations (1), we define the scalar uncoupled differential operators

$$
\mathcal{L}_{i, \varepsilon} v(\mathbf{x}, t) \equiv v_{t}(\mathbf{x}, t)-\varepsilon^{2}\left(v_{x x}(\mathbf{x}, t)+v_{y y}(\mathbf{x}, t)\right)+a_{i i} v(\mathbf{x}, t), i=1,2, \ldots, \ell,
$$

which clearly satisfy a maximum principle [19]. Then, it is straightforward to prove the following result (see [13, Lemma 2.1]).

Lemma 1 Let $w \in C(\bar{Q}) \cap C^{2}(Q)$ be such that $\mathcal{L}_{i, \varepsilon} w=\psi$ on $Q$ and $w=\varphi$ on $\Gamma$. Then, it holds

$$
\|w\|_{\bar{Q}} \leq\left\|\frac{\psi}{a_{i i}}\right\|_{\bar{Q}}+\|\varphi\|_{\Gamma} .
$$

Using the differential operators given in (5) and following closely the proof [13, Lemma 2.2], the following result can be proved. 
Lemma 2 Let $\mathbf{u}$ be a solution of (1). For $k=0,1,2, \ldots$, define the sequence of functions $\mathbf{u}^{[k]}=\left(u_{1}^{[k]}, u_{2}^{[k]}, \ldots, u_{\ell}^{[k]}\right)$ as follows: let $\mathbf{u}^{[0]}$ be any function in $(C(\bar{Q}))^{\ell}$, and for $k=0,1,2, \ldots$, let $\mathbf{u}^{[k]}$ such that

$$
\mathcal{L}_{i, \varepsilon} u_{i}^{[k]}=f_{i}-\sum_{j \neq i} a_{i j} u_{i}^{[k-1]}, \text { on } Q, u_{i}^{[k]}=0, \text { on } \Gamma, i=1,2, \ldots, \ell \text {. }
$$

Then, it holds $\lim _{k \rightarrow \infty} \mathbf{u}^{[k]}=\mathbf{u}$. Moreover, we have

$$
\|\mathbf{u}\|_{\bar{Q}} \leq \frac{1}{\beta(1-\gamma)}\|\mathbf{f}\|_{\bar{Q}}
$$

where $0 \leq \gamma \equiv \max _{i} \gamma_{i}<1$ and $\gamma_{i}=\max _{\bar{Q}}\left\{\frac{1}{a_{i i}} \sum_{j \neq i}\left|a_{i j}\right|\right\}, i=1,2, \ldots, \ell$.

From Lemma 2, the existence of a unique solution of problem (1) and the maximum principle are deduced. The latest is given in next result.

Lemma 3 (Maximum Principle) Let $\mathbf{v} \in\left(C(\bar{Q}) \cap C^{2}(Q)\right)^{\ell}$ be such that $\mathcal{L}_{\varepsilon} \mathbf{v} \geq$ 0 on $Q$ and $\mathbf{v} \geq 0$ on $\Gamma$. Then, $\mathbf{v} \geq 0$ on $\bar{Q}$.

For the analysis of the uniform convergence of the numerical method, we need precise information about the asymptotic behavior of the solution $\mathbf{u}$ of (1). Following, for example, [9], it is easy to establish bounds for the time derivatives of the solution, which are bounded independently of the singular perturbation parameter $\varepsilon$.

Lemma 4 Let $\mathbf{u}$ be the solution of (1). Then, there exists $C$ independent of E such that

$$
\left\|\frac{\partial^{k} \mathbf{u}}{\partial t^{k}}\right\|_{\bar{Q}} \leq C, \quad 0 \leq k \leq 2
$$

Next, we give some estimates for the space (and crossed) derivatives of u. In a similar way that in $[22,24]$ (cf. [4] and [13] for 2D elliptic problems of reaction-diffusion type in the case of scalar and vector unknowns, respectively), the solution of (1) can be decomposed as

$$
\mathbf{u}=\mathbf{v}+\sum_{i=1}^{4} \mathbf{w}_{i}+\sum_{i=1}^{4} \mathbf{z}_{i}
$$

where the component $\mathbf{v}$ satisfies

$$
\left|\frac{\partial^{k+k_{0}}}{\partial x^{k_{1}} \partial y^{k_{2}} \partial t^{k_{0}}} \mathbf{v}(\mathbf{x}, t)\right| \leq \mathbf{C}\left(1+\varepsilon^{2-k}\right), \quad(\mathbf{x}, t) \in \bar{Q}, \quad 0 \leq k+2 k_{0} \leq 4,
$$


with $k=k_{1}+k_{2}$, the boundary layer components $w_{i}, i=1,2,3,4$, for $(\mathbf{x}, t) \in \bar{Q}$ satisfy

$$
\begin{aligned}
& \left|\mathbf{w}_{i}(\mathbf{x}, t)\right| \leq \mathbf{C} e^{-\alpha_{0} \varepsilon^{-1} r\left(\mathbf{x}, \Gamma_{i}\right)}, \quad(\mathbf{x}, t) \in \bar{Q}, \quad i=1,2,3,4, \\
& \left|\frac{\partial^{k_{0}}}{\partial t^{k_{0}}} \mathbf{w}_{i}(\mathbf{x}, t)\right| \leq \mathbf{C}, \quad(\mathbf{x}, t) \in \bar{Q}, \quad 1 \leq k_{0} \leq 2, \quad i=1,2,3,4 \\
& \left|\frac{\partial^{k}}{\partial x^{k_{1}} \partial y^{k_{2}}} \mathbf{w}_{i}(\mathbf{x}, t)\right| \leq \mathbf{C} \varepsilon^{-k_{1}}, \quad(\mathbf{x}, t) \in \bar{Q}, \quad 0 \leq k \leq 4, \quad i=2,4, \\
& \left|\frac{\partial^{k}}{\partial x^{k_{1}} \partial y^{k_{2}}} \mathbf{w}_{i}(\mathbf{x}, t)\right| \leq \mathbf{C} \varepsilon^{-k_{2}}, \quad(\mathbf{x}, t) \in \bar{Q}, \quad 0 \leq k \leq 4, \quad i=1,3
\end{aligned}
$$

and the corner layer components $\mathbf{z}_{i}, i=1,2,3,4$, satisfy

$$
\begin{aligned}
& \left|\mathbf{z}_{i}(\mathbf{x}, t)\right| \leq \mathbf{C} e^{-\alpha_{0} \varepsilon^{-1} r\left(\mathbf{x}, \Gamma_{i} \cap \Gamma_{i+1}\right)}, \quad(\mathbf{x}, t) \in \bar{Q}, \\
& \left|\frac{\partial^{k_{0}}}{\partial t^{k_{0}}} \mathbf{z}_{i}(\mathbf{x}, t)\right| \leq \mathbf{C}, \quad(\mathbf{x}, t) \in \bar{Q}, \quad 1 \leq k_{0} \leq 2, \\
& \left|\frac{\partial^{k}}{\partial x^{k_{1}} \partial y^{k_{2}}} \mathbf{z}_{i}(\mathbf{x}, t)\right| \leq \mathbf{C} \varepsilon^{-k}, \quad(\mathbf{x}, t) \in \bar{Q}, \quad 0 \leq k \leq 4,
\end{aligned}
$$

where $\alpha_{0}$ is an arbitrary positive constant such that

$$
0<\alpha_{0}<\alpha,
$$

and $r\left(\mathbf{x}, \Gamma_{i}\right)$ and $r\left(\mathbf{x}, \Gamma_{i} \cap \Gamma_{i+1}\right)$ are the distance from the point $\mathbf{x}$ to the sets $\Gamma_{i}$ and $\Gamma_{i} \cap \Gamma_{i+1}$, respectively. For the sake of brevity, in (16) we have made use of the notation $\Gamma_{5}=\Gamma_{1}$.

Remark 1 Error estimates similar to (27) can be obtained if one has the following cruder estimates

$$
\begin{aligned}
& \left|\frac{\partial^{k_{2}}}{\partial y^{k_{2}}} \mathbf{w}_{i}(\mathbf{x}, t)\right| \leq \mathbf{C} \varepsilon^{2-k_{2}}, \quad(\mathbf{x}, t) \in \bar{Q}, \quad 0 \leq k_{2} \leq 4, \quad i=2,4, \\
& \left|\frac{\partial^{k_{1}}}{\partial x^{k_{1}}} \mathbf{w}_{i}(\mathbf{x}, t)\right| \leq \mathbf{C} \varepsilon^{2-k_{1}}, \quad(\mathbf{x}, t) \in \bar{Q}, \quad 0 \leq k_{1} \leq 4, \quad i=1,3,
\end{aligned}
$$

of the derivatives of the components $\mathbf{w}_{i}, i=1,2,3,4$, in the direction orthogonal to the boundary layer associated to them. We refer to [4] for further details, where a scalar elliptic problem of reaction-diffusion type is considered.

\section{The fully discrete method: uniform convergence}

In this section we construct the numerical methods to approximate (1) and we prove that they are uniformly convergent with respect to the diffusion parameter $\varepsilon$. These schemes are motivated by the Jacobi iteration from Lemma 2 and [17], and they were used in the case of $1 \mathrm{D}$ problem in space in [1], where the efficiency of the additive schemes for singularly perturbed problems was revealed. 
Firstly, we discretize (1) in time. For that, we consider a uniform mesh $\bar{\omega}^{M}=\left\{t_{m}=m \tau, 0 \leq m \leq M, \tau=T / M\right\}$, where $M$ is a positive integer. Then the discretization with the additive schemes [26] is given by

$$
\begin{aligned}
& \mathbf{z}^{0}=\mathbf{u}(\mathbf{x}, 0)=\mathbf{0}, \text { in } \Omega, \\
& \left\{\begin{array}{l}
\text { For } m=0,1, \ldots, M-1, \\
\tau^{-1}\left(\mathbf{z}^{m+1}-\mathbf{z}^{m}\right)-\mathcal{D} \Delta \mathbf{z}^{m+1}+\mathcal{M}^{m+1} \mathbf{z}^{m+1}-\mathcal{N}^{m+1} \mathbf{z}^{m}=\mathbf{f}^{m+1}, \text { in } \Omega, \\
\mathbf{z}^{m+1}=\mathbf{0}, \text { on } \partial \Omega,
\end{array}\right.
\end{aligned}
$$

where $\mathbf{f}^{m+1}=\mathbf{f}\left(\mathbf{x}, t_{m+1}\right), m=0,1, \ldots, M-1$, and the matrix $\mathcal{A}\left(\mathbf{x}, t_{m+1}\right)=$ $\mathcal{A}^{m+1}(\mathbf{x})$ is decomposed as

$$
\mathcal{A}^{m+1}(\mathbf{x})=\mathcal{M}^{m+1}(\mathbf{x})-\mathcal{N}^{m+1}(\mathbf{x}) .
$$

We shall consider two different additive schemes. In the first one, the matrix $\mathcal{M}^{m+1}$ is the diagonal part of the matrix $\mathcal{A}^{m+1}(\mathbf{x})$, i.e.,

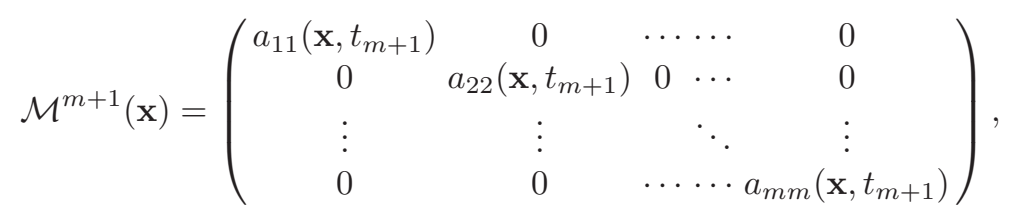

and, in the second one, the lower triangular part of the matrix $\mathcal{A}^{m+1}(\mathbf{x})$, i.e.,

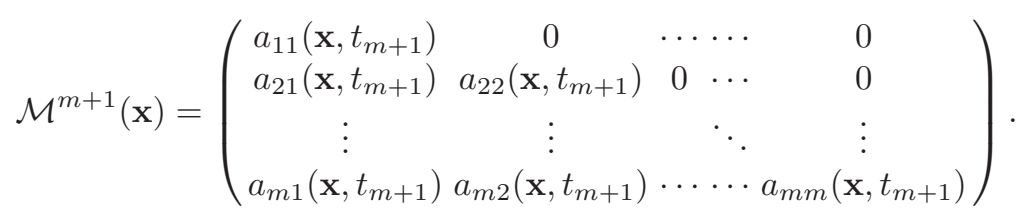

In this way, at the time level $t_{m+1}$, the components of the vector unknown $\mathbf{z}^{m+1}$ are decoupled for both schemes. All the theoretical results that follows are true for both additive schemes and they are written in a general form.

For the discretization (20) the following result holds and this proves the uniform convergence of the time discretization.

Lemma $\mathbf{5}$ Let $\mathbf{u}$ and $\mathbf{z}^{m+1}$ be the solution of problems (1) and (20), respectively. Then, it holds

$$
\left|\mathbf{u}\left(\mathbf{x}, t_{m+1}\right)-\mathbf{z}^{m+1}(\mathbf{x})\right| \leq \mathbf{C} \tau, \forall \mathbf{x} \in \bar{\Omega}
$$

and therefore the additives scheme are first-order uniformly convergent methods.

Proof It is an easy adaptation of the proofs given in [2] or [9]. 
In previous works (see $[1,3,5]$ for instance), auxiliary semidiscrete problems were defined and those problems were discretized in space by using different finite difference schemes. To analyze the uniform convergence of the spatial discretization, it is necessary to know the asymptotic behavior of the exact solution of these semidiscrete auxiliary problems, which is an additional task. Nevertheless, in this paper we consider directly the fully discrete scheme, and its uniform convergence is proved.

To construct the fully discrete scheme, we discretize (20) with the classical central difference scheme, which is defined on a specially nonuniform mesh $\bar{\Omega}^{N} \equiv I_{x, \varepsilon}^{N} \times I_{y, \varepsilon}^{N}, I_{x, \varepsilon}^{N}=\left\{0=x_{0}<\ldots<x_{N}=1\right\}, I_{y, \varepsilon}^{N}=\left\{0=y_{0}<\ldots<\right.$ $\left.y_{N}=1\right\}$, as a tensor product of one dimensional meshes.

In Section 2 we have shown that the solution of problem (1) exhibits a parabolic boundary layer at $\partial \Omega$ and corner layers in the neighborhood of the edges of the domain where the boundary layers intersect. Then, the meshes $I_{x, \varepsilon}^{N}$ and $I_{y, \varepsilon}^{N}$ are defined so that $\bar{\Omega}^{N}$ condenses in the layer regions. We consider in both spatial directions a piecewise uniform Shishkin mesh. We only give the details of the construction of $I_{x, \varepsilon}^{N}$ and it is similarly done for $I_{y, \varepsilon}^{N}$. For simplicity, in the present work we take the same value of $N$ for both spatial variables; it could be made in a similar way if the numbers of grid points in the spatial directions differ.

Let $N$ be a positive integer that is divisible by 4 . The grid points of the piecewise uniform Shishkin mesh, in the $x$-spatial variable, are given by (see $[6])$

$$
x_{j}= \begin{cases}j h, & j=0, \ldots, N / 4, \\ x_{N / 4}+(j-N / 4) H, & j=N / 4+1, \ldots, 3 N / 4, \\ x_{3 N / 4}+(j-3 N / 4) h, & j=3 N / 4+1, \ldots, N,\end{cases}
$$

with $h=4 \sigma / N, H=2(1-2 \sigma) / N$, and $\sigma$ is the transition parameter of the Shishkin mesh given by

$$
\sigma=\min \left\{1 / 4,\left(2 / \alpha_{0}\right) \varepsilon \ln N\right\},
$$

where the positive constant $0<\alpha_{0}<\alpha$ is defined in (19). In the following, it is assumed that $\sigma=\left(2 / \alpha_{0}\right) \varepsilon \ln N$, that is the interesting case in practice. Otherwise, $N$ is exponentially large compared to $\varepsilon^{-1}$.

We denote by $\bar{Q}^{N, M}=\bar{\Omega}^{N} \times \bar{\omega}^{M}$ the grid for the $(\mathbf{x}, t)$-variables, $Q^{N, M}=$ $\bar{Q}^{N, M} \cap Q, \Gamma^{N, M}=\bar{Q}^{N, M} \backslash Q^{N, M}, \mathbf{U}=\left\{\mathbf{U}^{0}, \ldots, \mathbf{U}^{M}\right\}$ the vector numerical approximation on the grid $\bar{Q}^{N, M}$ with $\mathbf{U}^{m}=\left\{\mathbf{U}_{00}^{m}, \ldots, \mathbf{U}_{i j}^{m}, \ldots, \mathbf{U}_{N N}^{m}\right\}, 0 \leq$ $m \leq M$ and $\mathbf{U}_{i j}^{m}=\left\{\left(U_{i j}^{m}\right)_{1}, \ldots,\left(U_{i j}^{m}\right)_{\ell}\right\}$ for $0 \leq m \leq M$ and $0 \leq i, j \leq N$. Then, the fully discrete scheme is giving by

$$
\begin{aligned}
& \mathbf{U}^{0}=\mathbf{0}, \\
& \left\{\begin{array}{l}
\text { For } m=0,1, \ldots, M-1, \\
{\left[L_{\varepsilon}^{N, M} \mathbf{U}\right]^{m+1}=\mathbf{f}^{m+1}, \text { on } \Omega^{N},} \\
\mathbf{U}_{0 j}^{m+1}=\mathbf{U}_{N j}^{m+1}=\mathbf{U}_{j 0}^{m+1}=\mathbf{U}_{j N}^{m+1}=\mathbf{0}, j=0,1, \ldots, N,
\end{array}\right.
\end{aligned}
$$

where

$\left[L_{\varepsilon}^{N, M} \mathbf{U}\right]^{m+1} \equiv \tau^{-1}\left(\mathbf{U}^{m+1}-\mathbf{U}^{m}\right)-\mathcal{D}\left(\delta_{x}^{2}+\delta_{y}^{2}\right) \mathbf{U}^{m+1}+\mathcal{M}^{m+1} \mathbf{U}^{m+1}-\mathcal{N}^{m+1} \mathbf{U}^{m}$, 
and

$$
\begin{aligned}
\delta_{x}^{2} Z_{i, j} & =\frac{2}{h_{x, i}+h_{x, i+1}}\left(\frac{Z_{i+1, j}-Z_{i, j}}{h_{x, i+1}}-\frac{Z_{i, j}-Z_{i-1, j}}{h_{x, i}}\right), \\
\delta_{y}^{2} Z_{i, j} & =\frac{2}{h_{y, j}+h_{y, j+1}}\left(\frac{Z_{i, j+1}-Z_{i, j}}{h_{y, j+1}}-\frac{Z_{i, j}-Z_{i, j-1}}{h_{y, j}}\right),
\end{aligned}
$$

are the standard approximations of the second order derivative for each spatial variable on a nonuniform mesh, with $h_{x, i}=x_{i}-x_{i-1}, h_{y, j}=y_{j}-y_{j-1}, i, j=$ $1, \ldots, N$.

Similarly to the continuous problem, a discrete maximum principle is satisfied by the difference operator $L_{\varepsilon}^{N, M}$. This can be verified using the Mcriterion [20, Theorem 2.7] and taking $\mathbf{e}=\mathbf{1}$ as the test vector. Thus, from the hypothesis (3) and the M-criterion, it follows

$$
\left\|\left(L_{\varepsilon}^{N, M}\right)^{-1}\right\|_{\infty} \leq 1 / \alpha^{2}
$$

and the matrix associated to the operator $L_{\varepsilon}^{N, M}$ is an M-matrix. Therefore, the discrete comparison principle is satisfied by the $L_{\varepsilon}^{N, M}$. This principle, together with appropriate barrier functions, is crucial to obtain the final error estimate.

Lemma 6 (Discrete comparison principle) Let $\mathbf{G}$ be a grid function. Assume that $L_{\varepsilon}^{N, M} \mathbf{G} \geq \mathbf{0}$ on $Q^{N, M}$ and $\mathbf{G} \geq \mathbf{0}$ on $\Gamma^{N, M}$. Then, $\mathbf{G} \geq \mathbf{0}$ on $\bar{Q}^{N, M}$.

Theorem 1 below is the main result of this paper, in which error estimates for the numerical scheme (25) are established. In the proof, similarly to the continuous problem, we use a decomposition of the discrete solution given by

$$
\mathbf{U}=\mathbf{V}+\sum_{i=1}^{4} \mathbf{W}_{i}+\sum_{i=1}^{4} \mathbf{Z}_{i}
$$

where these grid functions are the solutions of the discrete problems

$$
\begin{aligned}
& L_{\varepsilon}^{N, M} \mathbf{V}=\mathcal{L}_{\varepsilon} \mathbf{v} \text { on } Q^{N, M}, \quad \text { and } \mathbf{V}=\mathbf{v} \text { on } \Gamma^{N, M}, \\
& L_{\varepsilon}^{N, M} \mathbf{W}_{i}=\mathbf{0} \text { on } Q^{N, M}, \quad \text { and } \mathbf{W}_{i}=\mathbf{w}_{i} \text { on } \Gamma^{N, M}, \\
& L_{\varepsilon}^{N, M} \mathbf{Z}_{i}=\mathbf{0} \text { on } Q^{N, M}, \quad \text { and } \mathbf{Z}_{i}=\mathbf{z}_{i} \text { on } \Gamma^{N, M},
\end{aligned}
$$

for $i=1,2,3,4$. Appropriate error estimates are deduced for each one of these components and, in consequence, for $\|\mathbf{U}-\mathbf{u}\|_{\bar{Q}^{N, M}}$.

We use an argument based on appropriate barrier functions to prove the errors estimates associated to the boundary and corner layers functions. We 
consider the usual barrier functions

$$
\begin{aligned}
& \left(B_{w_{1} ; i j}^{m}\right)_{l}=\left\{\begin{array}{l}
\prod_{s=1}^{j}\left(1+h_{y, s} \alpha_{0} / \varepsilon\right)^{-1}, j \neq 0, \\
1, j=0,
\end{array}\right. \\
& \left(B_{w_{2} ; i j}^{m}\right)_{l}=\left\{\begin{array}{l}
\prod_{s=1}^{i}\left(1+h_{x, s} \alpha_{0} / \varepsilon\right)^{-1}, i \neq 0, \\
1, i=0,
\end{array}\right. \\
& \left(B_{w_{3} ; i j}^{m}\right)_{l}=\left\{\begin{array}{l}
\prod_{s=j+1}^{N}\left(1+h_{y, s} \alpha_{0} / \varepsilon\right)^{-1}, j \neq N, \\
1, j=N,
\end{array}\right. \\
& \left(B_{w_{4} ; i j}^{m}\right)_{l}=\left\{\begin{array}{l}
\prod_{s=i+1}^{N}\left(1+h_{x, s} \alpha_{0} / \varepsilon\right)^{-1}, i \neq N, \\
1, i=N,
\end{array}\right.
\end{aligned}
$$

for $0 \leq m \leq M, 0 \leq i, j \leq N$ and $1 \leq l \leq \ell$. The discrete comparison principle and the hypothesis (3) prove

$$
\left|\mathbf{W}_{i}\right| \leq \mathbf{B}_{w_{i}},\left|\mathbf{Z}_{i}\right| \leq \mathbf{B}_{w_{i}} \mathbf{B}_{w_{i+1}},
$$

for $i=1,2,3,4$, where we have defined the grid function $\mathbf{B}_{w_{5}}=\mathbf{B}_{w_{1}}$ for notational convenience.

In the proof of next Theorem, we use the well-known estimates (see, for instance [20, Section 2.4])

$$
\left(B_{w_{1} ; i j}^{m}\right)_{l} \leq C N^{-2}, \quad \text { for } y_{j} \geq \sigma,
$$

and analogous bounds are satisfied for the other three barrier functions.

Theorem 1 Let $\mathbf{U}$ be the numerical solution of (25) on the Shishkin mesh and $\mathbf{u}$ the solution of (1). Then, it holds

$$
\|\mathbf{U}-\mathbf{u}\|_{\bar{Q}^{N, M}} \leq C\left(\tau+\left(N^{-1} \ln N\right)^{2}\right),
$$

where $C$ is a positive constant independent of the diffusion parameter $\varepsilon$ and the discretization parameters $N$ and $M$. Therefore, the fully discrete scheme is a uniformly convergent method of first order in time and almost second order in space.

Proof Consider first the component v. From (11), it follows

$$
\left|v_{i}\left(\mathbf{x}, t_{m+1}\right)-v_{i}\left(\mathbf{x}, t_{m}\right)\right| \leq C \tau\left\|\frac{\partial v_{i}}{\partial t}\right\|_{\bar{Q}} \leq C \tau,
$$

and therefore

$$
\left|\mathcal{A}^{m+1} \mathbf{v}\left(\mathbf{x}, t_{m+1}\right)-\left(\mathcal{M}^{m+1} \mathbf{v}\left(\mathbf{x}, t_{m+1}\right)-\mathcal{N}^{m+1} \mathbf{v}\left(\mathbf{x}, t_{m}\right)\right)\right| \leq \mathbf{C} \tau .
$$


Using the estimates (11), the truncation error for the regular component satisfies

$$
\begin{aligned}
\mid L_{\varepsilon}^{N, M} & (\mathbf{V}-\mathbf{v})\left(x_{i}, y_{j}, t_{m+1}\right)|\leq| \frac{\partial}{\partial t} \mathbf{v}\left(x_{i}, y_{j}, t_{m+1}\right)-\frac{\mathbf{v}\left(x_{i}, y_{j}, t_{m+1}\right)-\mathbf{v}\left(x_{i}, y_{j}, t_{m}\right)}{\tau} \mid \\
& +\mathcal{D}\left|\Delta \mathbf{v}\left(x_{i}, y_{j}, t_{m+1}\right)-\left(\delta_{x}^{2}+\delta_{y}^{2}\right) \mathbf{v}\left(x_{i}, y_{j}, t_{m+1}\right)\right| \\
& +\left|\mathcal{A}^{m+1} \mathbf{v}\left(x_{i}, y_{j}, t_{m+1}\right)-\left(\mathcal{M}^{m+1} \mathbf{v}\left(x_{i}, y_{j}, t_{m+1}\right)-\mathcal{N}^{m+1} \mathbf{v}\left(x_{i}, y_{j}, t_{m}\right)\right)\right| \\
& \leq \mathbf{C} \tau+\mathcal{D}\left|\Delta \mathbf{v}\left(x_{i}, y_{j}, t_{m+1}\right)-\left(\delta_{x}^{2}+\delta_{y}^{2}\right) \mathbf{v}\left(x_{i}, y_{j}, t_{m+1}\right)\right| .
\end{aligned}
$$

The estimates for the last term depends on the location of the point $\left(x_{i}, y_{j}, t_{m+1}\right)$ on the piecewise uniform Shishkin mesh. It is not difficult to prove that it holds

$$
\left|L_{\varepsilon}^{N, M}(\mathbf{V}-\mathbf{v})\left(x_{i}, y_{j}, t_{m+1}\right)\right| \leq \mathbf{C} \tau+\left\{\begin{array}{l}
\mathbf{C} N^{-1} \varepsilon, \text { if } x_{i}=\sigma, 1-\sigma, \text { or } y_{j}=\sigma, 1-\sigma, \\
\mathbf{C} N^{-2}, \text { otherwise. }
\end{array}\right.
$$

Nevertheless, from (28) we cannot deduce directly the almost second order of uniform convergence in space. Then, to improve this estimate for the component $\mathbf{v}$, we proceed as follows. We define the barrier function

$$
\Theta=\mathbf{C} \tau+\mathbf{C} \frac{\sigma^{2}}{\varepsilon^{2}} N^{-2}\left(\theta\left(x_{i}\right)+\theta\left(y_{j}\right)\right),
$$

where $\theta(z)$ is the usual piecewise linear polynomial (see for example [4]), defined by

$$
\theta(z)=\left\{\begin{array}{l}
\frac{z}{\sigma}, 0 \leq z \leq \sigma \\
1, \sigma \leq z \leq 1-\sigma \\
\frac{1-z}{\sigma}, 1-\sigma \leq z \leq 1
\end{array}\right.
$$

From the choice of transition points, it follows that $|\Theta| \leq \mathbf{C}\left(\tau+\left(N^{-1} \ln N\right)^{2}\right)$. Then, the discrete comparison principle proves

$$
\left|(\mathbf{V}-\mathbf{v})\left(x_{i}, y_{j}, t_{m+1}\right)\right| \leq \Theta \leq \mathbf{C}\left(\tau+\left(N^{-1} \ln N\right)^{2}\right) .
$$

We now consider the boundary layer functions $\mathbf{w}_{i}, i=1,2,3,4$. We only give the details for the function $\mathbf{w}_{1}$ and one can use an analogous argument for the other three functions. Using the exponential decreasing (12) of this component and the barrier function $\mathbf{B}_{w_{1}}$, we obtain

$$
\left|\left(\mathbf{W}_{1}-\mathbf{w}_{1}\right)\left(x_{i}, y_{j}, t_{m+1}\right)\right| \leq \mathbf{C} e^{-\alpha_{0} \varepsilon^{-1} y_{j}}+\mathbf{B}_{w_{1}} .
$$

Hence,

$$
\left|\left(\mathbf{W}_{1}-\mathbf{w}_{1}\right)\left(x_{i}, y_{j}, t_{m+1}\right)\right| \leq \mathbf{C} N^{-2}, \quad \text { if } \sigma \leq y_{j} \leq 1 .
$$

Error estimates for this component at the grid points $\left(x_{i}, y_{j}, t_{m}\right) \in(0,1) \times$ $(0, \sigma) \times(0, T]$ are proved using a truncation error argument. From the bounds (13), (15) and the mesh width in the $y$-direction, we obtain

$$
\begin{aligned}
\left|L_{\varepsilon}^{N, M}(\mathbf{W}-\mathbf{w})\left(x_{i}, y_{j}, t_{m+1}\right)\right| \leq & \mathbf{C} \tau+\mathbf{C}\left(N^{-1} \ln N\right)^{2} \\
& +\left\{\begin{array}{l}
\mathbf{C} N^{-1} \varepsilon, \text { if } x_{i}=\sigma, 1-\sigma, \\
\mathbf{C} N^{-2}, \text { otherwise }
\end{array}\right.
\end{aligned}
$$


These estimates, the barrier function

$$
\tilde{\Theta}=\mathbf{C} \tau+\mathbf{C} N^{-2} \ln ^{2} N+\mathbf{C} \frac{\sigma^{2}}{\varepsilon^{2}} N^{-2} \theta\left(x_{i}\right),
$$

and the discrete maximum principle applied to the subdomain $[0,1] \times[0, \sigma] \times$ $[0, T]$ prove

$$
\left|\left(\mathbf{W}_{1}-\mathbf{w}_{1}\right)\left(x_{i}, y_{j}, t_{m+1}\right)\right| \leq \mathbf{C}\left(\tau+\left(N^{-1} \ln N\right)^{2}\right), \quad \text { if } 0 \leq y_{j} \leq \sigma .
$$

Finally, we consider the corner layer functions $\mathbf{z}_{i}, i=1,2,3,4$. As above, we only give the details for one of these functions; for example $\mathbf{z}_{1}$. If $x_{i} \geq \sigma$, then we deduce error estimates for this component using that it decays exponentially from $y=0$ and the definition of the transition point $\sigma$; then, we have

$$
\left|\left(\mathbf{Z}_{1}-\mathbf{z}_{1}\right)\left(x_{i}, y_{j}, t_{m+1}\right)\right| \leq \mathbf{C} e^{-\alpha_{0} \varepsilon^{-1} y_{j}}+\mathbf{B}_{w_{1}} \leq C N^{-2}, \text { if } y_{j} \geq \sigma .
$$

If $x_{i} \geq \sigma$, using that $\mathbf{z}_{1}$ decays exponentially from $x=0$, it holds

$$
\left|\left(\mathbf{Z}_{1}-\mathbf{z}_{1}\right)\left(x_{i}, y_{j}, t_{m+1}\right)\right| \leq \mathbf{C} e^{-\alpha_{0} \varepsilon^{-1} x_{i}}+\mathbf{B}_{w_{2}} \leq C N^{-2}, \quad \text { if } x_{i} \geq \sigma .
$$

In the region $(0, \sigma)^{2} \times(0, T]$ the errors estimates are deduced using a truncation error argument and that the mesh is fine in both spatial directions. In this region, the following estimate holds

$$
\left|L_{\varepsilon}^{N, M}\left(\mathbf{Z}_{1}-\mathbf{z}_{1}\right)\left(x_{i}, y_{j}, t_{m+1}\right)\right| \leq \mathbf{C} \tau+\mathbf{C}\left(N^{-1} \ln N\right)^{2}, \quad \text { if } 0<x_{i}, y_{j}<\sigma,
$$

and therefore applying the discrete maximum principle to the subdomain $[0, \sigma]^{2} \times[0, T]$, we obtain

$$
\left|\left(\mathbf{Z}_{1}-\mathbf{z}_{1}\right)\left(x_{i}, y_{j}, t_{m+1}\right)\right| \leq \mathbf{C}\left(\tau+\left(N^{-1} \ln N\right)^{2}\right), \quad \text { if } 0 \leq x_{i}, y_{j} \leq \sigma .
$$

The above estimates (29)-(35) (analogous estimates for the other boundary and corner layer components) prove the required result.

\section{The multigrid algorithm}

The scheme (25) decouples the numerical components of the discrete solution at each time level and then we have to solve $\ell$ discrete problems; each one of them is associated to the discretization with central differences of a $2 \mathrm{D}$ scalar problem of reaction-diffusion type. In order to solve efficiently the $\ell$ linear systems at each time level, we use a multigrid method.

Elliptic boundary value problems are the class of problems to which multigrid methods can be applied efficiently if they are discretized with numerical methods defined on uniform or quasi uniform meshes. Nevertheless, the Shishkin mesh, which has been used to construct the numerical scheme (25), is very anisotropic at the transition points (the ratio of the mesh step sizes depends on $\varepsilon$ ) and it causes difficulties to multigrid algorithms. In previous 
papers, different strategies have been followed to overcome these difficulties. In $[7,8]$ the authors propose to use special grid transfer operators from the fine-to-coarse meshes; in [15] a block preconditioner is carefully designed and, more recently, a multigrid method based on a patched mesh method is proposed in [11].

In this paper we follow the first strategy. In particular, the geometric multigrid algorithm uses a simple $V$-cycle, standard coarsening (i.e., doubling the mesh size in every direction), bilinear interpolation as the transfer operator from the coarse-to-fine meshes and standard pointwise smoothing methods (as relaxed Jacobi, Gauss-Seidel and their red-black versions). The coarsest grid used in the multigrid algorithm has only one interior point. The only special component of the multigrid algorithm is the restriction operator from the fine-to-coarse meshes.

A restriction operator $R_{N}^{N / 2}$ (N denotes the number of grid points in each spatial direction and it is assumed to be a power of 2), maps fine-grid functions $G^{N}$ onto coarse-grid functions $G^{N / 2}$

$$
\begin{aligned}
& R_{N}^{N / 2}: \bar{\Omega}^{N} \rightarrow \bar{\Omega}^{N / 2} \\
& G^{N} \rightarrow R_{N}^{N / 2} G^{N}=G^{N / 2}
\end{aligned}
$$

which is usually represented using the stencil notation [25]

$$
R_{N}^{N / 2}=\left[\begin{array}{ccc}
r_{-1,1} & r_{0,1} & r_{1,1} \\
r_{-1,0} & r_{0,0} & r_{1,0} \\
r_{-1,-1} & r_{0,-1} & r_{1,-1}
\end{array}\right]
$$

and it means

$$
\begin{array}{r}
G^{N / 2}\left(x_{i}, y_{j}\right)=\sum_{m, n=-1}^{1} r_{m, n} G^{N}\left(x_{i}+m h_{x, i+(m-1) / 2}, y_{j}+n h_{y, j+(n-1) / 2}\right), \\
\left(x_{i}, y_{j}\right) \in \bar{\Omega}^{N} .
\end{array}
$$

The restriction operators can be defined by interpreting that $r_{m, n}$ are the coefficients of appropriate quadrature rules. Following the ideas given in [7, 8] for $2 \mathrm{D}$ singularly perturbed scalar problems with a convective term, one can construct appropriate restriction operators in the case of $2 \mathrm{D}$ problems of reaction-diffusion type. The restriction operator depends on the location of the point $\left(x_{i}, y_{j}\right)$ on the mesh $\bar{\Omega}^{N}$ and, in the case of the reaction-diffusion problem, we propose the following restriction operators:

$$
R_{N}^{N / 2}=\frac{1}{4}\left[\begin{array}{ccc}
0 & 0 & 0 \\
1-\sigma & 2(1-\sigma) & 1-\sigma \\
\sigma & 2 \sigma & \sigma
\end{array}\right], \quad \text { for }\left(x_{i}, \sigma\right), x_{i} \neq \sigma, 1-\sigma
$$

(similarly are defined at the points $\left(x_{i}, 1-\sigma\right),\left(\sigma, y_{j}\right)$ and $\left(1-\sigma, y_{j}\right)$ with $\left.x_{i}, y_{j} \neq \sigma, 1-\sigma\right)$,

$$
R_{N}^{N / 2}=\left[\begin{array}{ccc}
0 & 0 & 0 \\
\sigma(1-\sigma) & (1-\sigma)^{2} & 0 \\
\sigma^{2} & \sigma(1-\sigma) & 0
\end{array}\right], \quad \text { for }(\sigma, \sigma)
$$


(similarly are defined at the points $(\sigma, 1-\sigma),(1-\sigma, \sigma)$ and $(1-\sigma, 1-\sigma))$,

$$
R_{N}^{N / 2}=\frac{1}{16}\left[\begin{array}{lll}
1 & 2 & 1 \\
2 & 4 & 2 \\
1 & 2 & 1
\end{array}\right], \quad \text { otherwise }
$$

(this last is the classical full-weighting operator).

Observe that we only have nine different expressions for the transition operator as the Shishkin mesh has the desirable property of being a piecewise uniform mesh. This is very convenient in practice and thence the interest of using a mesh of Shishkin type.

\section{Numerical results}

In this section we show the numerical results obtained for two test problems of type (1), which have two and three equations respectively. Although both examples only satisfy compatibility conditions of zero-order, which do not guarantee that the solution $\mathbf{u} \in C^{4,2}(\bar{Q})$, they illustrate in practice the error estimates proved in Theorem 1 and also the efficiency of the numerical scheme.

In both examples we consider the additive scheme (22) and we have reached similar conclusions if (21) is used instead. The linear systems are solved using the multigrid method described in Section 4. Recall that, at each time level, we solve as many linear systems as equations has the system. In all cases we use a multigrid V-cycle with one pre- and one post-smoothing iteration with the standard Gauss-Seidel method and lexicographic ordering. Whenever the multigrid algorithm is used to solve a linear system of the form $L_{\varepsilon}^{N, M} \mathbf{U}^{m+1}=$ $\mathbf{f}^{m+1}$, the stopping criterion is

$$
\left\|\mathbf{f}^{m+1}-L_{\varepsilon}^{N, M} \mathbf{U}_{\mathrm{it}}^{m+1}\right\|_{\infty} \leq \mathrm{tol}
$$

where the subscript it denotes the iteration step of the multigrid algorithm and tol is the tolerance error. In practice, the stopping criterion could be associated with the actual error (27), but we take a more restrictive value for the tolerance to show the performance of our method. In all the numerical experiments the tolerance is a fixed value given by tol $=10^{-5}$, and similar results have been obtained for smaller values of the tolerance.

Example 1 The first example is defined when the reaction matrix and the right-hand side are

$$
\begin{aligned}
\mathcal{A} & =\left(\begin{array}{cc}
1+t^{2}\left(x^{2}+y^{2}\right) & -2 t^{2} x y \\
-\sin \left(x y \frac{\pi}{2}\right) & 2+3 t^{2}
\end{array}\right), \\
\mathbf{f} & =\left(\begin{array}{l}
t^{2}(x(1-x)+y(1-y)) e^{x} \\
\left(1-e^{-t}\right)(\sin (\pi x)+\sin (\pi y))\left(1+y^{2}\right)
\end{array}\right),
\end{aligned}
$$

respectively, and the final time is $T=1$. The exact solution of problem (1) and (37) is unknown and it is approximated with the scheme (25) on the Shishkin mesh with $\alpha_{0}=1$ in (24). 
Figure 1 displays the numerical solution, at $t=0.5$ and $t=1$, using the scheme (25) when the discretization parameters are $N=64, M=48$ and the diffusion parameter is $\varepsilon=10^{-4}$. From it, we clearly see the boundary layers at the four sides of the spatial domain.

Fig. 1 Components $u_{1}$ (first row) and $u_{2}$ (second row) at $t=0.5$ (left figures) and $t=1$ (right figures) of Example 1 for $\varepsilon^{2}=10^{-4}$ with $N=64$ and $M=32$
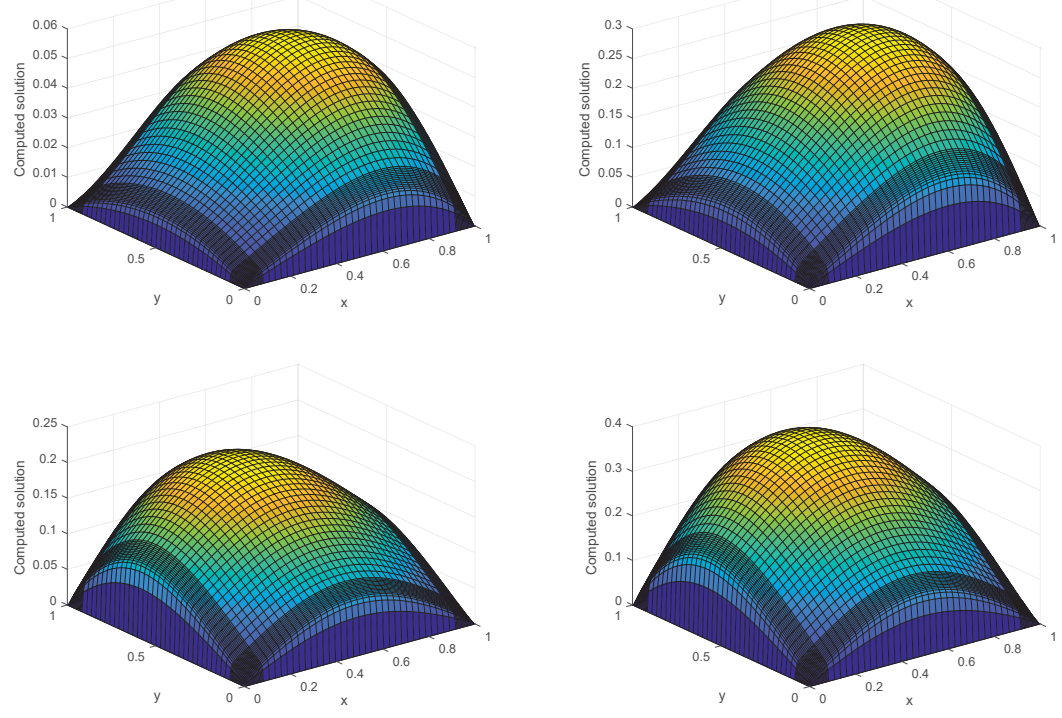

As the exact solution is unknown, we cannot calculate exactly the errors; to approximate them, we use a variant of the double-mesh principle [6]. Then, the maximum errors for each value of $\varepsilon$ are approximated by

$$
\mathbf{d}_{\varepsilon}^{N, M}=\max _{0 \leq m \leq M} \max _{0 \leq i, j \leq N}\left|\mathbf{U}_{i, j}^{m}-\widehat{\mathbf{U}}_{2 i, 2 j}^{2 m}\right|
$$

where $\left\{\widehat{\mathbf{U}}_{i, j}^{m}\right\}$ is the numerical solution on a finer mesh $\left\{\left(\hat{x}_{i}, \hat{y}_{j}, \hat{t}_{m}\right)\right\}$, which has the mesh points of the coarse mesh and their midpoints, i.e.,

$$
\begin{aligned}
& \hat{x}_{2 i}=x_{i}, \quad i=0, \ldots, N, \quad \hat{x}_{2 i+1}=\left(x_{i}+x_{i+1}\right) / 2, \quad i=0, \ldots, N-1, \\
& \hat{y}_{2 j}=y_{j}, \quad j=0, \ldots, N, \quad \hat{y}_{2 j+1}=\left(y_{j}+y_{j+1}\right) / 2, \quad j=0, \ldots, N-1, \\
& \hat{t}_{2 m}=t_{m}, \quad m=0, \ldots, M, \quad \hat{t}_{2 m+1}=\left(t_{m}+t_{m+1}\right) / 2, \quad m=0, \ldots, M-1 .
\end{aligned}
$$

From the maximum two-mesh differences $\mathbf{d}_{\varepsilon}^{N, M}$, we obtain the $\varepsilon$-uniform twomesh differences by

$$
\mathbf{d}^{N, M}=\max _{\varepsilon} \mathbf{d}_{\varepsilon}^{N, M} .
$$


From the approximated maximum errors $\mathbf{d}_{\varepsilon}^{N, M}$, in a standard way, the numerical orders of convergence, for each value of $\varepsilon$, are calculated by

$$
p_{\varepsilon}^{N, M}=\log \left(\mathbf{d}_{\varepsilon}^{N, M} / \mathbf{d}_{\varepsilon}^{2 N, 2 M}\right) / \log 2,
$$

and from the approximated uniform maximum errors $\mathbf{d}^{N, M}$, the numerical uniform orders of convergence are calculated by

$$
p^{N, M}=\log \left(\mathbf{d}^{N, M} / \mathbf{d}^{2 N, 2 M}\right) / \log 2 .
$$

Tables 1 and 2 show the maximum two-mesh differences and the orders of convergence for the components $u_{1}$ and $u_{2}$ respectively; from them, we clearly deduce that the method is first-order uniformly convergent. Moreover, we can conclude that the errors associated to the time discretization dominate into the global error of the numerical method. In addition, we give the maximum number of iterations that the multigrid algorithm needs to convergence to the numerical solution at all the time levels. In order to show the robustness of the multigrid algorithm with respect to the parameters $\varepsilon, N$ and $M$ we take the initial guess of the iteration as zero, without using any information on the values of the solution. Observe that very few iterations are required by the multigrid algorithm and this number of iterations stabilizes when $\varepsilon$ decreases.

Table 1 Example 1: Maximum and uniform two-mesh differences and their orders of convergence for the component $u_{1}$. Maximum number of iterations for all the times levels in brackets

\begin{tabular}{|c||c|c|c|c|c|c|}
\hline & $\mathrm{N}=16$ & $\mathrm{~N}=32$ & $\mathrm{~N}=64$ & $\mathrm{~N}=128$ & $\mathrm{~N}=256$ & $\mathrm{~N}=512$ \\
\hline & $\mathrm{M}=8$ & $\mathrm{M}=16$ & $\mathrm{M}=32$ & $\mathrm{M}=64$ & $\mathrm{M}=128$ & $\mathrm{M}=256$ \\
\hline \hline$\varepsilon^{2}=1$ & $2.074 \mathrm{E}-4(7)$ & $1.145 \mathrm{E}-4(8)$ & $5.980 \mathrm{E}-5(8)$ & $3.053 \mathrm{E}-5(8)$ & $1.543 \mathrm{E}-5(9)$ & $7.754 \mathrm{E}-6(9)$ \\
& 0.858 & 0.937 & 0.970 & 0.985 & 0.993 & \\
\hline$\varepsilon^{2}=10^{-1}$ & $4.813 \mathrm{E}-3(6)$ & $2.521 \mathrm{E}-3(7)$ & $1.288 \mathrm{E}-3(7)$ & $6.512 \mathrm{E}-4(7)$ & $3.273 \mathrm{E}-4(8)$ & $1.641 \mathrm{E}-4(8)$ \\
& 0.933 & 0.969 & 0.984 & 0.992 & 0.996 & \\
\hline$\varepsilon^{2}=10^{-2}$ & $1.185 \mathrm{E}-2(4)$ & $5.955 \mathrm{E}-3(5)$ & $2.978 \mathrm{E}-3(5)$ & $1.489 \mathrm{E}-3(6)$ & $7.441 \mathrm{E}-4(6)$ & $3.720 \mathrm{E}-4(6)$ \\
& 0.993 & 1.000 & 1.000 & 1.000 & 1.000 & \\
\hline$\varepsilon^{2}=10^{-3}$ & $1.277 \mathrm{E}-2(2)$ & $6.369 \mathrm{E}-3(3)$ & $3.174 \mathrm{E}-3(3)$ & $1.584 \mathrm{E}-3(4)$ & $7.913 \mathrm{E}-4(4)$ & $3.955 \mathrm{E}-4(4)$ \\
& 1.004 & 1.005 & 1.003 & 1.001 & 1.001 & \\
\hline$\varepsilon^{2}=10^{-4}$ & $1.284 \mathrm{E}-2(2)$ & $6.399 \mathrm{E}-3(3)$ & $3.192 \mathrm{E}-3(3)$ & $1.593 \mathrm{E}-3(4)$ & $7.957 \mathrm{E}-4(4)$ & $3.976 \mathrm{E}-4(4)$ \\
& 1.004 & 1.003 & 1.003 & 1.001 & 1.001 & \\
\hline$\varepsilon^{2}=10^{-5}$ & $1.277 \mathrm{E}-2(2)$ & $6.408 \mathrm{E}-3(3)$ & $3.192 \mathrm{E}-3(3)$ & $1.594 \mathrm{E}-3(4)$ & $7.957 \mathrm{E}-4(4)$ & $3.976 \mathrm{E}-4(4)$ \\
& 0.995 & 1.005 & 1.002 & 1.001 & 1.001 & \\
\hline$\varepsilon^{2}=10^{-6}$ & $1.274 \mathrm{E}-2(2)$ & $6.411 \mathrm{E}-3(3)$ & $3.194 \mathrm{E}-3(3)$ & $1.594 \mathrm{E}-3(4)$ & $7.957 \mathrm{E}-4(4)$ & $3.976 \mathrm{E}-4(4)$ \\
& 0.991 & 1.005 & 1.003 & 1.001 & 1.001 & \\
\hline$\varepsilon^{2}=10^{-7}$ & $1.273 \mathrm{E}-2(2)$ & $6.412 \mathrm{E}-3(3)$ & $3.194 \mathrm{E}-3(3)$ & $1.594 \mathrm{E}-3(4)$ & $7.957 \mathrm{E}-4(4)$ & $3.976 \mathrm{E}-4(4)$ \\
& 0.990 & 1.005 & 1.003 & 1.001 & 1.001 & \\
\hline$\varepsilon^{2}=10^{-8}$ & $1.273 \mathrm{E}-2(2)$ & $6.412 \mathrm{E}-3(3)$ & $3.194 \mathrm{E}-3(3)$ & $1.594 \mathrm{E}-3(4)$ & $7.957 \mathrm{E}-4(4)$ & $3.976 \mathrm{E}-4(4)$ \\
& 0.989 & 1.005 & 1.003 & 1.001 & 1.001 & \\
\hline$\varepsilon^{2}=10^{-9}$ & $1.273 \mathrm{E}-2(2)$ & $6.412 \mathrm{E}-3(3)$ & $3.194 \mathrm{E}-3(3)$ & $1.594 \mathrm{E}-3(4)$ & $7.957 \mathrm{E}-4(4)$ & $3.976 \mathrm{E}-4(4)$ \\
& 0.989 & 1.005 & 1.003 & 1.001 & 1.001 & \\
\hline$\varepsilon^{2}=10^{-10}$ & $1.273 \mathrm{E}-2(2)$ & $6.412 \mathrm{E}-3(3)$ & $3.194 \mathrm{E}-3(3)$ & $1.594 \mathrm{E}-3(4)$ & $7.957 \mathrm{E}-4(4)$ & $3.976 \mathrm{E}-4(4)$ \\
& 0.989 & 1.005 & 1.003 & 1.001 & 1.001 & \\
\hline$d_{1}^{N, M}$ & $1.284 \mathrm{E}-2$ & $6.412 \mathrm{E}-3$ & $3.194 \mathrm{E}-3$ & $1.594 \mathrm{E}-3$ & $7.957 \mathrm{E}-4$ & $3.976 \mathrm{E}-4$ \\
$p_{1}^{N}, M$ & 1.001 & 1.005 & 1.003 & 1.001 & 1.001 & \\
\hline
\end{tabular}

In Tables 3 and 4 the discretization parameters are multiplied by different factors, $N$ by 2 and $M$ by 4 respectively, so that the errors associated with the spatial discretization dominate into the global errors. The computed orders of 
Table 2 Example 1: Maximum and uniform two-mesh differences and their orders of convergence for the component $u_{2}$. Maximum number of iterations for all the times levels in brackets

\begin{tabular}{|c|c|c|c|c|c|c|}
\hline & $\begin{array}{l}\mathrm{N}=16 \\
\mathrm{M}=8\end{array}$ & $\begin{array}{l}\mathrm{N}=32 \\
\mathrm{M}=16\end{array}$ & $\begin{array}{l}\mathrm{N}=64 \\
\mathrm{M}=32\end{array}$ & $\mathrm{~N}=128$ & $\mathrm{~N}=256$ & $\begin{array}{l}\mathrm{N}=512 \\
\mathrm{M}=256\end{array}$ \\
\hline$\varepsilon^{2}=1$ & $8.443 \mathrm{E}-4(8)$ & $4.534 \mathrm{E}-4(8)$ & $2.857 \mathrm{E}-4(9)$ & $1.699 \mathrm{E}-4(9)$ & $9.377 \mathrm{E}-5(9)$ & $4.943 \mathrm{E}-5(10)$ \\
\hline & 0.897 & 0.666 & 0.750 & 0.857 & 0.924 & \\
\hline$\varepsilon^{2}=10^{-1}$ & $\begin{array}{c}8.654 \mathrm{E}-3(6) \\
0.959\end{array}$ & $\begin{array}{c}4.451 \mathrm{E}-3(7) \\
0.980\end{array}$ & $\begin{array}{c}2.257 \mathrm{E}-3(7) \\
0.990\end{array}$ & $\begin{array}{c}1.136 \mathrm{E}-3(7) \\
0.995\end{array}$ & $\begin{array}{c}5.702 \mathrm{E}-4(8) \\
0.997\end{array}$ & $2.856 \mathrm{E}-4(8)$ \\
\hline$\varepsilon^{2}=10^{-2}$ & $\begin{array}{c}1.466 \mathrm{E}-2(4) \\
1.023\end{array}$ & $\begin{array}{c}7.214 \mathrm{E}-3(5) \\
1.014\end{array}$ & $\begin{array}{c}3.573 \mathrm{E}-3(5) \\
1.008\end{array}$ & $\begin{array}{c}1.777 \mathrm{E}-3(6) \\
1.004\end{array}$ & $\begin{array}{c}8.858 \mathrm{E}-4(6) \\
1.002\end{array}$ & $4.423 \mathrm{E}-4(6)$ \\
\hline$\varepsilon^{2}=10^{-3}$ & $\begin{array}{c}1.534 \mathrm{E}-2(2) \\
1.029\end{array}$ & $\begin{array}{c}7.518 \mathrm{E}-3(3) \\
1.017\end{array}$ & $\begin{array}{c}3.715 \mathrm{E}-3(3) \\
1.009\end{array}$ & $\begin{array}{c}1.846 \mathrm{E}-3(4) \\
1.005\end{array}$ & $\begin{array}{c}9.197 \mathrm{E}-4(4) \\
1.002\end{array}$ & $4.591 \mathrm{E}-4(4)$ \\
\hline$\varepsilon^{2}=10^{-4}$ & $\begin{array}{c}1.529 \mathrm{E}-2(2) \\
1.018\end{array}$ & $\begin{array}{c}7.546 \mathrm{E}-3(3) \\
1.018\end{array}$ & $\begin{array}{c}3.727 \mathrm{E}-3(3) \\
1.009\end{array}$ & $\begin{array}{c}1.852 \mathrm{E}-3(4) \\
1.005\end{array}$ & $\begin{array}{c}9.230 \mathrm{E}-4(4) \\
1.002\end{array}$ & $4.607 \mathrm{E}-4(4)$ \\
\hline$\varepsilon^{2}=10^{-5}$ & $\begin{array}{c}1.532 \mathrm{E}-2(2) \\
1.022\end{array}$ & $\begin{array}{c}7.547 \mathrm{E}-3(3) \\
1.017\end{array}$ & $\begin{array}{c}3.728 \mathrm{E}-3(3) \\
1.009\end{array}$ & $\begin{array}{c}1.853 \mathrm{E}-3(4) \\
1.005\end{array}$ & $\begin{array}{c}9.230 \mathrm{E}-4(4) \\
1.002\end{array}$ & $4.607 \mathrm{E}-4(4)$ \\
\hline$\varepsilon^{2}=10^{-6}$ & $\begin{array}{c}1.533 \mathrm{E}-2(2) \\
1.023\end{array}$ & $\begin{array}{c}7.544 \mathrm{E}-3(3) \\
1.017\end{array}$ & $\begin{array}{c}3.728 \mathrm{E}-3(3) \\
1.009\end{array}$ & $\begin{array}{c}1.853 \mathrm{E}-3(4) \\
1.005\end{array}$ & $\begin{array}{c}9.230 \mathrm{E}-4(4) \\
1.002\end{array}$ & $4.607 \mathrm{E}-4(4)$ \\
\hline$\varepsilon^{2}=10^{-7}$ & $\begin{array}{c}1.534 \mathrm{E}-2(2) \\
1.024\end{array}$ & $\begin{array}{c}7.543 \mathrm{E}-3(3) \\
1.017\end{array}$ & $\begin{array}{c}3.728 \mathrm{E}-3(3) \\
1.009\end{array}$ & $\begin{array}{c}1.853 \mathrm{E}-3(4) \\
1.005\end{array}$ & $\begin{array}{c}9.230 \mathrm{E}-4(4) \\
1.002\end{array}$ & $4.607 \mathrm{E}-4(4)$ \\
\hline$\varepsilon^{2}=10^{-8}$ & $\begin{array}{c}1.534 \mathrm{E}-2(2) \\
1.024\end{array}$ & $\begin{array}{c}7.542 \mathrm{E}-3(3) \\
1.016\end{array}$ & $\begin{array}{c}3.728 \mathrm{E}-3(3) \\
1.009\end{array}$ & $\begin{array}{c}1.853 \mathrm{E}-3(4) \\
1.005\end{array}$ & $\begin{array}{c}9.230 \mathrm{E}-4(4) \\
1.002\end{array}$ & $4.607 \mathrm{E}-4(4)$ \\
\hline$\varepsilon^{2}=10^{-9}$ & $\begin{array}{c}1.534 \mathrm{E}-2(2) \\
1.024\end{array}$ & $\begin{array}{c}7.542 \mathrm{E}-3(3) \\
1.016\end{array}$ & $\begin{array}{c}3.728 \mathrm{E}-3(3) \\
1.009\end{array}$ & $\begin{array}{c}1.853 \mathrm{E}-3(4) \\
1.005\end{array}$ & $\begin{array}{c}9.230 \mathrm{E}-4(4) \\
1.002\end{array}$ & $4.607 \mathrm{E}-4(4)$ \\
\hline$\varepsilon^{2}=10^{-10}$ & $\begin{array}{c}1.534 \mathrm{E}-2(2) \\
1.024\end{array}$ & $\begin{array}{c}7.542 \mathrm{E}-3(3) \\
1.016\end{array}$ & $\begin{array}{c}3.728 \mathrm{E}-3(3) \\
1.009\end{array}$ & $\begin{array}{c}1.853 \mathrm{E}-3(4) \\
1.005\end{array}$ & $\begin{array}{c}9.230 \mathrm{E}-4(4) \\
1.002\end{array}$ & $4.607 \mathrm{E}-4(4)$ \\
\hline $\begin{array}{l}d_{2, M}^{N, M} \\
p_{2}^{N, M}\end{array}$ & $1.534 \mathrm{E}-2$ & $7.547 \mathrm{E}-3$ & $3.728 \mathrm{E}-3$ & $1.853 \mathrm{E}-3$ & $9.230 \mathrm{E}-4$ & $4.607 \mathrm{E}-4$ \\
\hline
\end{tabular}

convergence now show almost second order of convergence, in agreement with Theorem 1. The maximum number of iterations with the multigrid algorithm are also given and they show again its robustness for all the values of $\varepsilon$.

Example 2 In the second example the reaction matrix and the right-hand side are

$$
\begin{aligned}
& \mathcal{A}=\left(\begin{array}{ccc}
1+4 t^{3}+t e^{x+y} & -t(x+y) & -t x \\
-t(x+y) & 2+3 \cos (t)+t(x+y) & -t \cos (y) \\
-t x & -t \sin (y) & 1+t e^{x}+2 t^{2}(1-t)
\end{array}\right) \\
& \mathbf{f}=\left(\begin{array}{l}
t^{3}(\sin (\pi x(1-x))+\sin (\pi y(1-y)))^{2} \\
\left(1-e^{-t}\right)(x(1-x)+y(1-y))^{2} e^{x}(y-x) \\
\left(2 t^{3}-(x+y) t^{2}\right)(\cos (0.5 \pi(x+y)) \sin (\pi(x+y)))^{3}
\end{array}\right)
\end{aligned}
$$

respectively, and the final time is again $T=1$. The solution of this example is approximated with the scheme (25) on the Shishkin mesh with $\alpha_{0}=1$ in (24).

The computed solutions with the finite difference scheme (25) at $t=0.5$ and $t=1$ are displayed in Figure 2. These surfaces show the presence of boundary layers for the three components of the solution.

Similarly to the previous example, we show the numerical results for each component in separate tables. The maximum two-mesh differences and the orders of convergence for $u_{i}, i=1,2,3$ are given in Tables 5-7 respectively, where the discretization parameters $N$ and $M$ are multiplied by a factor of 2 . The tolerance error is again tol $=10^{-5}$. The $\varepsilon$-uniform computed orders of convergence again agree with Theorem 1 . The maximum number of iterations, 
Table 3 Example 1: Maximum and uniform two-mesh differences and their orders of convergence for the component $u_{1}$. Maximum number of iterations for all the times levels in brackets

\begin{tabular}{|c|c|c|c|c|c|}
\hline & $\begin{array}{l}\mathrm{N}=16 \\
\mathrm{M}=16\end{array}$ & $\begin{array}{l}\mathrm{N}=32 \\
\mathrm{M}=64\end{array}$ & $\begin{array}{c}N=64 \\
M=256\end{array}$ & $\mathrm{~N}=128$ & $\mathrm{~N}=256$ \\
\hline$\varepsilon^{2}=1$ & $1.015 \mathrm{E}-4(7)$ & $2.659 \mathrm{E}-5(7)$ & & & $4.199 \mathrm{E}-7(8)$ \\
\hline & $\begin{array}{c}1.0102-4(1) \\
1.933 \\
\end{array}$ & $\begin{array}{c}2.009 \mathrm{~L}-3 \\
1.985 \\
\end{array}$ & $\begin{array}{r}0.012 \\
2.017 \\
\end{array}$ & $\begin{array}{r}1.000 \mathrm{c}-6 \\
1.988 \\
\end{array}$ & $4.199 \mathrm{E}-1$ (8) \\
\hline$\varepsilon^{2}=10^{-1}$ & $\begin{array}{c}2.335 \mathrm{E}-3(6) \\
1.976\end{array}$ & $\begin{array}{c}5.934 \mathrm{E}-4(6) \\
1.994\end{array}$ & $\begin{array}{c}1.489 \mathrm{E}-4(6) \\
1.999\end{array}$ & $\begin{array}{c}3.726 \mathrm{E}-5(6) \\
2.000 \\
\end{array}$ & $9.317 \mathrm{E}-6(7)$ \\
\hline$\varepsilon^{2}=10^{-2}$ & $\begin{array}{c}.904 \mathrm{E}-3(3) \\
1.999 \\
\end{array}$ & $\begin{array}{c}1.477 \mathrm{E}-3(4) \\
2.000\end{array}$ & $\begin{array}{c}3.692 \mathrm{E}-4(4) \\
2.000 \\
\end{array}$ & $\begin{array}{c}9.233 \mathrm{E}-5(4) \\
2.000 \\
\end{array}$ & $2.308 \mathrm{E}-5(4)$ \\
\hline$\varepsilon^{2}=10^{-3}$ & $\begin{array}{c}6.358 \mathrm{E}-3(2) \\
0.878 \\
\end{array}$ & $\begin{array}{c}3.460 \mathrm{E}-3(2) \\
1.097 \\
\end{array}$ & $\begin{array}{c}1.617 \mathrm{E}-3(2) \\
1.897 \\
\end{array}$ & $\begin{array}{c}4.342 \mathrm{E}-4(2) \\
1.972 \\
\end{array}$ & $1.107 \mathrm{E}-4(2)$ \\
\hline$\varepsilon^{2}=10^{-4}$ & $\begin{array}{c}6.365 \mathrm{E}-3(2) \\
0.858 \\
\end{array}$ & $\begin{array}{c}3.512 \mathrm{E}-3(2) \\
0.964\end{array}$ & $\begin{array}{c}1.801 \mathrm{E}-3(2) \\
1.449\end{array}$ & $\begin{array}{c}6.596 \mathrm{E}-4(2) \\
1.550\end{array}$ & $2.252 \mathrm{E}-4(2)$ \\
\hline$\varepsilon^{2}=10^{-5}$ & $\begin{array}{c}6.327 \mathrm{E}-3(2) \\
0.843 \\
\end{array}$ & $\begin{array}{c}3.527 \mathrm{E}-3(2) \\
0.968\end{array}$ & $\begin{array}{c}1.803 \mathrm{E}-3(2) \\
1.449 \\
\end{array}$ & $\begin{array}{c}6.602 \mathrm{E}-4(2) \\
1.551 \\
\end{array}$ & $2.253 \mathrm{E}-4(2)$ \\
\hline$\varepsilon^{2}=10^{-6}$ & $\begin{array}{c}6.310 \mathrm{E}-3(2) \\
0.837 \\
\end{array}$ & $\begin{array}{c}3.532 \mathrm{E}-3(2) \\
0.970 \\
\end{array}$ & $\begin{array}{c}1.804 \mathrm{E}-3(2) \\
1.450 \\
\end{array}$ & $\begin{array}{c}6.604 \mathrm{E}-4(2) \\
1.552 \\
\end{array}$ & $2.253 \mathrm{E}-4(2)$ \\
\hline$\varepsilon^{2}=10^{-7}$ & $\begin{array}{c}6.304 \mathrm{E}-3(2) \\
0.835\end{array}$ & $\begin{array}{c}3.534 \mathrm{E}-3(2) \\
0.970\end{array}$ & $\begin{array}{c}1.804 \mathrm{E}-3(2) \\
1.450\end{array}$ & $\begin{array}{c}6.604 \mathrm{E}-4(2) \\
1.552 \\
\end{array}$ & $2.253 \mathrm{E}-4(2)$ \\
\hline$\varepsilon^{2}=10^{-8}$ & $\begin{array}{c}6.303 \mathrm{E}-3(2) \\
0.834 \\
\end{array}$ & $\begin{array}{c}3.535 \mathrm{E}-3(2) \\
0.970 \\
\end{array}$ & $\begin{array}{c}1.804 \mathrm{E}-3(2) \\
1.450 \\
\end{array}$ & $\begin{array}{c}6.605 \mathrm{E}-4(2) \\
1.552 \\
\end{array}$ & $2.253 \mathrm{E}-4(2)$ \\
\hline$\varepsilon^{2}=10^{-9}$ & $\begin{array}{c}6.302 \mathrm{E}-3(2) \\
0.834 \\
\end{array}$ & $\begin{array}{c}3.535 \mathrm{E}-3(2) \\
0.970 \\
\end{array}$ & $\begin{array}{c}1.804 \mathrm{E}-3(2) \\
1.450\end{array}$ & $\begin{array}{c}6.605 \mathrm{E}-4(2) \\
1.552 \\
\end{array}$ & $2.253 \mathrm{E}-4(2)$ \\
\hline$\varepsilon^{2}=10^{-10}$ & $\begin{array}{c}6.302 \mathrm{E}-3(2) \\
0.834 \\
\end{array}$ & $\begin{array}{c}3.535 \mathrm{E}-3(2) \\
0.970 \\
\end{array}$ & $\begin{array}{c}1.804 \mathrm{E}-3(2) \\
1.450\end{array}$ & $\begin{array}{c}6.605 \mathrm{E}-4(2) \\
1.552 \\
\end{array}$ & $2.253 \mathrm{E}-4(2)$ \\
\hline $\begin{array}{l}d_{1, M}^{N, M} \\
p_{1}^{N, M}\end{array}$ & $\begin{array}{c}6.365 \mathrm{E}-3 \\
0.848 \\
\end{array}$ & $\begin{array}{c}3.535 \mathrm{E}-3 \\
0.970 \\
\end{array}$ & $\begin{array}{c}1.804 \mathrm{E}-3 \\
1.450\end{array}$ & $\begin{array}{c}6.605 \mathrm{E}-4 \\
1.552 \\
\end{array}$ & $2.253 \mathrm{E}-4$ \\
\hline
\end{tabular}

Table 4 Example 1: Maximum and uniform two-mesh differences and their orders of convergence for the component $u_{2}$. Maximum number of iterations for all the times levels in brackets

\begin{tabular}{|c|c|c|c|c|c|}
\hline & $\mathrm{N}=16$ & $\mathrm{~N}=32$ & $\mathrm{~N}=64$ & $\mathrm{~N}=128$ & $\mathrm{~N}=256$ \\
\hline & $\mathrm{M}=16$ & $\mathrm{M}=64$ & $\mathrm{M}=256$ & $\mathrm{M}=1024$ & $\mathrm{M}=4096$ \\
\hline$\varepsilon^{2}=1$ & $\begin{array}{c}4.378 \mathrm{E}-4(7) \\
1.372\end{array}$ & $\begin{array}{c}1.691 \mathrm{E}-4(8) \\
1.780\end{array}$ & $\begin{array}{c}4.924 \mathrm{E}-5(8) \\
1.939\end{array}$ & $\begin{array}{c}1.284 \mathrm{E}-5(8) \\
1.984\end{array}$ & $3.245 \mathrm{E}-6(8)$ \\
\hline$\varepsilon^{2}=10^{-1}$ & $\begin{array}{c}4.208 \mathrm{E}-3(6) \\
1.985\end{array}$ & $\begin{array}{c}1.063 \mathrm{E}-3(6) \\
1.995\end{array}$ & $\begin{array}{c}2.667 \mathrm{E}-4(6) \\
1.999\end{array}$ & $\begin{array}{c}6.674 \mathrm{E}-5(7) \\
2.000\end{array}$ & $1.669 \mathrm{E}-5(7)$ \\
\hline$\varepsilon^{2}=10^{-2}$ & $\begin{array}{c}7.186 \mathrm{E}-3(3) \\
2.023\end{array}$ & $\begin{array}{c}1.768 \mathrm{E}-3(4) \\
2.006\end{array}$ & $\begin{array}{l}4.402 \mathrm{E}-4(4) \\
2.001\end{array}$ & $\begin{array}{c}1.100 \mathrm{E}-4(4) \\
2.000\end{array}$ & $2.748 \mathrm{E}-5(4)$ \\
\hline$\varepsilon^{2}=10^{-3}$ & $\begin{array}{c}7.521 \mathrm{E}-3(2) \\
0.465\end{array}$ & $\begin{array}{c}5.450 \mathrm{E}-3(2) \\
0.919\end{array}$ & $\begin{array}{c}2.882 \mathrm{E}-3(2) \\
1.864\end{array}$ & $\begin{array}{c}7.919 \mathrm{E}-4(2) \\
1.962\end{array}$ & $2.033 \mathrm{E}-4(2)$ \\
\hline$\varepsilon^{2}=10^{-4}$ & $\begin{array}{c}7.490 \mathrm{E}-3(2) \\
0.441\end{array}$ & $\begin{array}{c}5.517 \mathrm{E}-3(2) \\
0.802\end{array}$ & $\begin{array}{c}3.165 \mathrm{E}-3(2) \\
1.467\end{array}$ & $\begin{array}{c}1.145 \mathrm{E}-3(2) \\
1.496\end{array}$ & $4.057 \mathrm{E}-4(2)$ \\
\hline$\varepsilon^{2}=10^{-5}$ & $\begin{array}{c}7.510 \mathrm{E}-3(2) \\
0.440\end{array}$ & $\begin{array}{c}5.537 \mathrm{E}-3(2) \\
0.805\end{array}$ & $\begin{array}{c}3.169 \mathrm{E}-3(2) \\
1.467\end{array}$ & $\begin{array}{c}1.146 \mathrm{E}-3(2) \\
1.497\end{array}$ & $4.060 \mathrm{E}-4(2)$ \\
\hline$\varepsilon^{2}=10^{-6}$ & $\begin{array}{c}7.515 \mathrm{E}-3(2) \\
0.439\end{array}$ & $\begin{array}{c}5.543 \mathrm{E}-3(2) \\
0.806\end{array}$ & $\begin{array}{c}3.170 \mathrm{E}-3(2) \\
1.468\end{array}$ & $\begin{array}{c}1.146 \mathrm{E}-3(2) \\
1.497\end{array}$ & $4.060 \mathrm{E}-4(2)$ \\
\hline$\varepsilon^{2}=10^{-7}$ & $\begin{array}{c}7.516 \mathrm{E}-3(2) \\
0.439 \\
\end{array}$ & $\begin{array}{c}5.545 \mathrm{E}-3(2) \\
0.807 \\
\end{array}$ & $\begin{array}{c}3.170 \mathrm{E}-3(2) \\
1.468\end{array}$ & $\begin{array}{c}1.146 \mathrm{E}-3(2) \\
1.497 \\
\end{array}$ & $4.060 \mathrm{E}-4(2)$ \\
\hline$\varepsilon^{2}=10^{-8}$ & $\begin{array}{c}7.517 \mathrm{E}-3(2) \\
0.439\end{array}$ & $\begin{array}{c}5.545 \mathrm{E}-3(2) \\
0.807\end{array}$ & $\begin{array}{c}3.170 \mathrm{E}-3(2) \\
1.468\end{array}$ & $\begin{array}{c}1.146 \mathrm{E}-3(2) \\
1.497\end{array}$ & $4.060 \mathrm{E}-4(2)$ \\
\hline$\varepsilon^{2}=10^{-9}$ & $\begin{array}{c}7.517 \mathrm{E}-3(2) \\
0.439\end{array}$ & $\begin{array}{c}5.545 \mathrm{E}-3(2) \\
0.807\end{array}$ & $\begin{array}{c}3.170 \mathrm{E}-3(2) \\
1.468\end{array}$ & $\begin{array}{c}1.146 \mathrm{E}-3(2) \\
1.497\end{array}$ & $4.060 \mathrm{E}-4(2)$ \\
\hline$\varepsilon^{2}=10^{-10}$ & $\begin{array}{c}7.517 \mathrm{E}-3(2) \\
0.439 \\
\end{array}$ & $\begin{array}{c}5.546 \mathrm{E}-3(2) \\
0.807 \\
\end{array}$ & $\begin{array}{c}3.170 \mathrm{E}-3(2) \\
1.468 \\
\end{array}$ & $\begin{array}{c}1.146 \mathrm{E}-3(2) \\
1497 \\
\end{array}$ & $4.060 \mathrm{E}-4(2)$ \\
\hline $\begin{array}{l}d_{2, M}^{N, M} \\
p_{2}^{N, M}\end{array}$ & $7.521 \mathrm{E}-3$ & $5.546 \mathrm{E}-3$ & $3.170 \mathrm{E}-3$ & $1.146 \mathrm{E}-3$ & $4.060 \mathrm{E}-4$ \\
\hline
\end{tabular}

that the multigrid algorithm needs to converge at all the times, are also given in the tables, showing again the robustness of the algorithm. 
Fig. 2 Components $u_{1}$ (first row), $u_{2}$ (second row) and $u_{3}$ (third row) at $t=0.5$ (left figures) and $t=1$ (right figures) of Example 2 for $\varepsilon^{2}=10^{-4}$ with $N=64$ and $M=32$
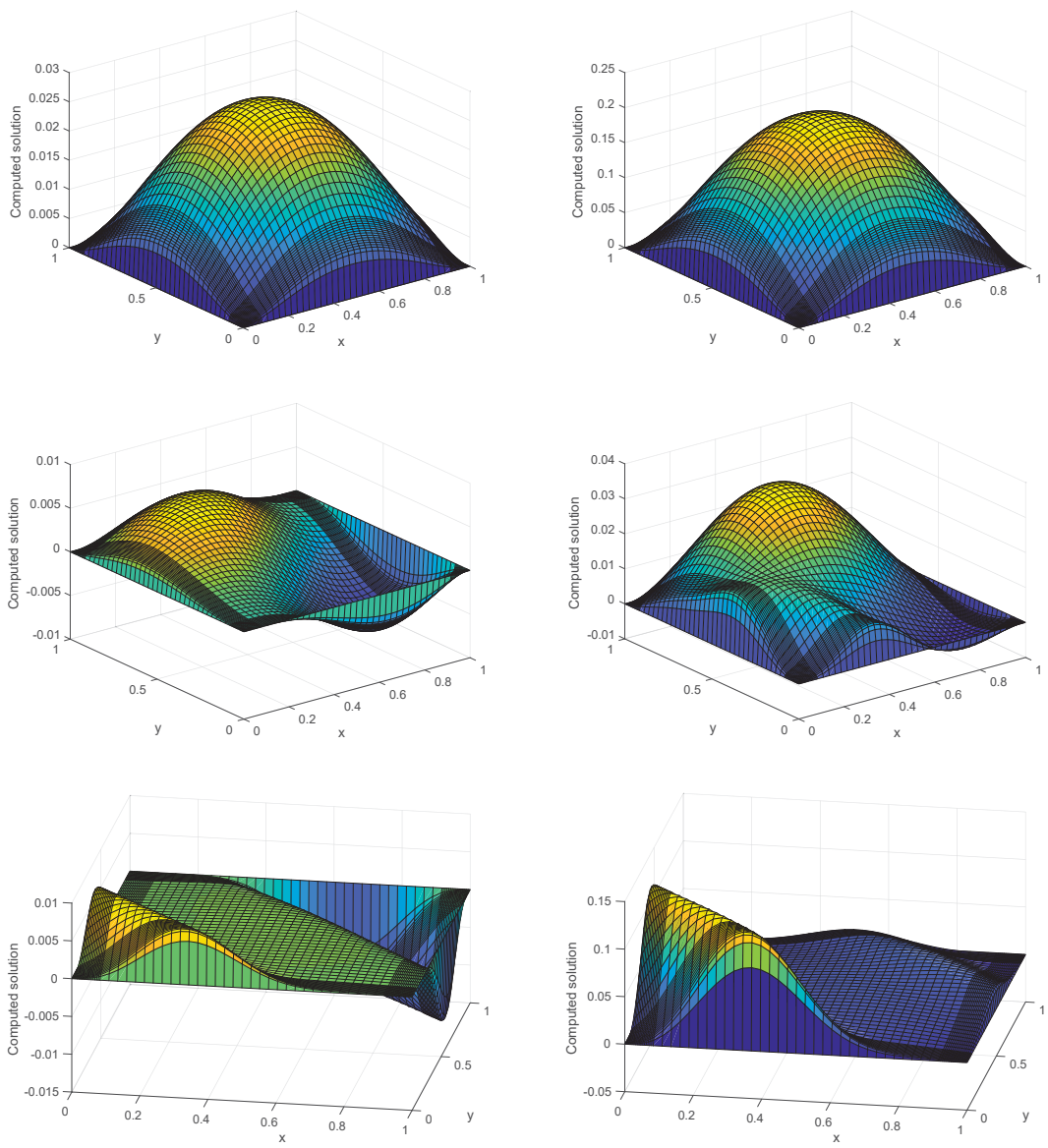

\section{Conclusions}

In this paper we have approximated 2D parabolic singularly perturbed system of reaction diffusion type with two additive finite difference schemes on a Shishkin mesh. If the diffusion parameter is the same in all equations of the system, both methods are uniformly convergent and they have first-order in time and almost second-order in space. The main advantage of the methods is that they decouple the approximation of each component of the vector solution, and therefore the computational cost is considerably smaller than for classical schemes. Moreover, we have used an adequate multigrid algorithm to solve the decoupled linear systems at each time level of the discretization. If the diffusion parameters have different order of magnitude, then overlapping boundary layers can appear at the boundary of the spatial domain. In that 
Table 5 Example 2: Maximum and uniform two-mesh differences and their orders of convergence for the component $u_{1}$. Maximum number of iterations for all the times levels in brackets

\begin{tabular}{|c||c|c|c|c|c|c|}
\hline \multicolumn{1}{|c|}{} & $\mathrm{N}=16$ & $\mathrm{~N}=32$ & $\mathrm{~N}=64$ & $\mathrm{~N}=128$ & $\mathrm{~N}=256$ & $\mathrm{~N}=512$ \\
\hline & $\mathrm{M}=8$ & $\mathrm{M}=16$ & $\mathrm{M}=32$ & $\mathrm{M}=64$ & $\mathrm{M}=128$ & $\mathrm{M}=256$ \\
\hline \hline$\varepsilon^{2}=1$ & $3.690 \mathrm{E}-4(7)$ & $1.833 \mathrm{E}-4(8)$ & $9.187 \mathrm{E}-5(8)$ & $4.601 \mathrm{E}-5(8)$ & $2.303 \mathrm{E}-5(8)$ & $1.152 \mathrm{E}-5(8)$ \\
& 1.009 & 0.997 & 0.998 & 0.999 & 0.999 & \\
\hline$\varepsilon^{2}=10^{-1}$ & $3.130 \mathrm{E}-3(6)$ & $1.729 \mathrm{E}-3(7)$ & $9.058 \mathrm{E}-4(7)$ & $4.641 \mathrm{E}-4(7)$ & $2.348 \mathrm{E}-4(7)$ & $1.181 \mathrm{E}-4(7)$ \\
& 0.857 & 0.932 & 0.965 & 0.983 & 0.991 & \\
\hline$\varepsilon^{2}=10^{-2}$ & $4.779 \mathrm{E}-3(3)$ & $2.656 \mathrm{E}-3(4)$ & $1.387 \mathrm{E}-3(5)$ & $7.088 \mathrm{E}-4(6)$ & $3.586 \mathrm{E}-4(6)$ & $1.803 \mathrm{E}-4(7)$ \\
& 0.847 & 0.938 & 0.968 & 0.983 & 0.992 & \\
\hline$\varepsilon^{2}=10^{-3}$ & $4.964 \mathrm{E}-3(2)$ & $2.765 \mathrm{E}-3(2)$ & $1.442 \mathrm{E}-3(3)$ & $7.375 \mathrm{E}-4(4)$ & $3.730 \mathrm{E}-4(4)$ & $1.875 \mathrm{E}-4(5)$ \\
& 0.844 & 0.940 & 0.967 & 0.984 & 0.992 & \\
\hline$\varepsilon^{2}=10^{-4}$ & $4.932 \mathrm{E}-3(2)$ & $2.768 \mathrm{E}-3(2)$ & $1.447 \mathrm{E}-3(3)$ & $7.403 \mathrm{E}-4(4)$ & $3.744 \mathrm{E}-4(5)$ & $1.883 \mathrm{E}-4(5)$ \\
& 0.833 & 0.936 & 0.967 & 0.983 & 0.992 & \\
\hline$\varepsilon^{2}=10^{-5}$ & $4.911 \mathrm{E}-3(2)$ & $2.772 \mathrm{E}-3(2)$ & $1.447 \mathrm{E}-3(3)$ & $7.406 \mathrm{E}-4(4)$ & $3.746 \mathrm{E}-4(5)$ & $1.883 \mathrm{E}-4(5)$ \\
& 0.825 & 0.938 & 0.966 & 0.983 & 0.992 & \\
\hline$\varepsilon^{2}=10^{-6}$ & $4.903 \mathrm{E}-3(2)$ & $2.773 \mathrm{E}-3(2)$ & $1.447 \mathrm{E}-3(3)$ & $7.406 \mathrm{E}-4(4)$ & $3.746 \mathrm{E}-4(5)$ & $1.883 \mathrm{E}-4(5)$ \\
& 0.822 & 0.938 & 0.966 & 0.983 & 0.992 & \\
\hline$\varepsilon^{2}=10^{-7}$ & $4.900 \mathrm{E}-3(2)$ & $2.774 \mathrm{E}-3(2)$ & $1.447 \mathrm{E}-3(3)$ & $7.406 \mathrm{E}-4(4)$ & $3.746 \mathrm{E}-4(5)$ & $1.883 \mathrm{E}-4(5)$ \\
& 0.821 & 0.939 & 0.966 & 0.983 & 0.992 & \\
\hline$\varepsilon^{2}=10^{-8}$ & $4.899 \mathrm{E}-3(2)$ & $2.774 \mathrm{E}-3(2)$ & $1.447 \mathrm{E}-3(3)$ & $7.406 \mathrm{E}-4(4)$ & $3.746 \mathrm{E}-4(5)$ & $1.883 \mathrm{E}-4(5)$ \\
& 0.821 & 0.939 & 0.966 & 0.983 & 0.992 & \\
\hline$\varepsilon^{2}=10^{-9}$ & $4.898 \mathrm{E}-3(2)$ & $2.774 \mathrm{E}-3(2)$ & $1.447 \mathrm{E}-3(3)$ & $7.406 \mathrm{E}-4(4)$ & $3.746 \mathrm{E}-4(5)$ & $1.883 \mathrm{E}-4(5)$ \\
& 0.820 & 0.939 & 0.966 & 0.983 & 0.992 & \\
\hline$\varepsilon^{2}=10^{-10}$ & $4.898 \mathrm{E}-3(2)$ & $2.774 \mathrm{E}-3(2)$ & $1.447 \mathrm{E}-3(3)$ & $7.406 \mathrm{E}-4(4)$ & $3.746 \mathrm{E}-4(5)$ & $1.883 \mathrm{E}-4(5)$ \\
& 0.820 & 0.939 & 0.966 & 0.983 & 0.992 & \\
\hline$d_{1}^{N, M}$ & $4.964 \mathrm{E}-3$ & $2.774 \mathrm{E}-3$ & $1.447 \mathrm{E}-3$ & $7.406 \mathrm{E}-4$ & $3.746 \mathrm{E}-4$ & $1.883 \mathrm{E}-4$ \\
$p_{1}^{N, M}$ & 0.840 & 0.939 & 0.967 & 0.983 & 0.992 & \\
\hline
\end{tabular}

case, the theoretical analysis of the asymptotic behavior of the exact solution and the error analysis of a uniformly convergent scheme are considerably more difficult tasks. To our knowledge, there are not previous works for that type of parabolic two dimensional coupled systems and it is a question that we will consider in a future work.

Acknowledgements The authors thank the referees their valuable suggestions which have helped to improve the presentation of this paper. This research was partially supported by the Instituto Universitario de Investigación en Matemáticas y Aplicaciones (IUMA), the projects MTM2017-83490-P and MTM2016-75139-R and the Diputación General de Aragón.

\section{References}

1. C. Clavero, J.L. Gracia, Uniformly convergent additive finite difference schemes for singularly perturbed parabolic reaction-diffusion system, Comput. Math. Appl. 67 (2014) 655-670.

2. C. Clavero, J.L. Gracia, J.C. Jorge, High-order numerical methods for one-dimensional parabolic singularly perturbed problems with regular layers, Numer. Methods Partial Differential Equations 21 (2005) 149-169.

3. C. Clavero, J.L. Gracia, F. Lisbona, Second order uniform approximations for the solution of time dependent singularly perturbed reaction-diffusion systems, Int. J. Numer. Anal. Mod. 7 (2010) 428-443.

4. C. Clavero, J.L. Gracia, E. O'Riordan, A parameter robust numerical method for a two dimensional reaction-diffusion problem, Math. Comp. 74 (2005) 1743-1758.

5. C. Clavero, J.C. Jorge, F. Lisbona, G.I. Shishkin, An alternating direction scheme on a nonuiform mesh for reaction-diffuion parabolic problems, IMA J. Numer. Anal. 20(2) (2000) 263-280. 
Table 6 Example 2: Maximum and uniform two-mesh differences and their orders of convergence for the component $u_{2}$. Maximum number of iterations for all the times levels in brackets

\begin{tabular}{|c||c|c|c|c|c|c|}
\hline \multicolumn{1}{|c|}{} & $\mathrm{N}=16$ & $\mathrm{~N}=32$ & $\mathrm{~N}=64$ & $\mathrm{~N}=128$ & $\mathrm{~N}=256$ & $\mathrm{~N}=512$ \\
\hline & $\mathrm{M}=8$ & $\mathrm{M}=16$ & $\mathrm{M}=32$ & $\mathrm{M}=64$ & $\mathrm{M}=128$ & $\mathrm{M}=256$ \\
\hline \hline$\varepsilon^{2}=1$ & $2.666 \mathrm{E}-5(6)$ & $1.180 \mathrm{E}-5(6)$ & $5.643 \mathrm{E}-6(6)$ & $2.843 \mathrm{E}-6(6)$ & $1.744 \mathrm{E}-6(6)$ & $9.686 \mathrm{E}-7(6)$ \\
& 1.176 & 1.064 & 0.989 & 0.705 & 0.848 & \\
\hline$\varepsilon^{2}=10^{-1}$ & $7.259 \mathrm{E}-4(5)$ & $3.984 \mathrm{E}-4(5)$ & $2.111 \mathrm{E}-4(5)$ & $1.085 \mathrm{E}-4(6)$ & $5.502 \mathrm{E}-5(6)$ & $2.771 \mathrm{E}-5(6)$ \\
& 0.866 & 0.916 & 0.961 & 0.980 & 0.990 & \\
\hline$\varepsilon^{2}=10^{-2}$ & $1.348 \mathrm{E}-3(3)$ & $7.494 \mathrm{E}-4(4)$ & $3.962 \mathrm{E}-4(4)$ & $2.039 \mathrm{E}-4(5)$ & $1.035 \mathrm{E}-4(5)$ & $5.214 \mathrm{E}-5(5)$ \\
& 0.847 & 0.919 & 0.959 & 0.978 & 0.989 & \\
\hline$\varepsilon^{2}=10^{-3}$ & $1.425 \mathrm{E}-3(2)$ & $7.916 \mathrm{E}-4(2)$ & $4.193 \mathrm{E}-4(3)$ & $2.158 \mathrm{E}-4(3)$ & $1.095 \mathrm{E}-4(4)$ & $5.518 \mathrm{E}-5(4)$ \\
& 0.848 & 0.917 & 0.958 & 0.978 & 0.989 & \\
\hline$\varepsilon^{2}=10^{-4}$ & $1.433 \mathrm{E}-3(2)$ & $8.019 \mathrm{E}-4(2)$ & $4.217 \mathrm{E}-4(3)$ & $2.170 \mathrm{E}-4(3)$ & $1.101 \mathrm{E}-4(4)$ & $5.550 \mathrm{E}-5(5)$ \\
& 0.837 & 0.927 & 0.959 & 0.978 & 0.989 & \\
\hline$\varepsilon^{2}=10^{-5}$ & $1.444 \mathrm{E}-3(2)$ & $8.182 \mathrm{E}-4(2)$ & $4.220 \mathrm{E}-4(3)$ & $2.171 \mathrm{E}-4(3)$ & $1.102 \mathrm{E}-4(4)$ & $5.553 \mathrm{E}-5(4)$ \\
& 0.819 & 0.955 & 0.958 & 0.978 & 0.989 & \\
\hline$\varepsilon^{2}=10^{-6}$ & $1.454 \mathrm{E}-3(2)$ & $8.212 \mathrm{E}-4(2)$ & $4.220 \mathrm{E}-4(3)$ & $2.171 \mathrm{E}-4(3)$ & $1.102 \mathrm{E}-4(4)$ & $5.553 \mathrm{E}-5(4)$ \\
& 0.824 & 0.961 & 0.958 & 0.978 & 0.989 & \\
\hline$\varepsilon^{2}=10^{-7}$ & $1.457 \mathrm{E}-3(2)$ & $8.219 \mathrm{E}-4(2)$ & $4.220 \mathrm{E}-4(3)$ & $2.171 \mathrm{E}-4(3)$ & $1.102 \mathrm{E}-4(4)$ & $5.553 \mathrm{E}-5(4)$ \\
& 0.826 & 0.962 & 0.958 & 0.978 & 0.989 & \\
\hline$\varepsilon^{2}=10^{-8}$ & $1.457 \mathrm{E}-3(2)$ & $8.221 \mathrm{E}-4(2)$ & $4.220 \mathrm{E}-4(3)$ & $2.171 \mathrm{E}-4(3)$ & $1.102 \mathrm{E}-4(4)$ & $5.553 \mathrm{E}-5(4)$ \\
& 0.826 & 0.962 & 0.958 & 0.978 & 0.989 & \\
\hline$\varepsilon^{2}=10^{-9}$ & $1.458 \mathrm{E}-3(2)$ & $8.221 \mathrm{E}-4(2)$ & $4.220 \mathrm{E}-4(3)$ & $2.171 \mathrm{E}-4(3)$ & $1.102 \mathrm{E}-4(4)$ & $5.553 \mathrm{E}-5(4)$ \\
& 0.826 & 0.962 & 0.958 & 0.978 & 0.989 & \\
\hline$\varepsilon^{2}=10^{-10}$ & $1.458 \mathrm{E}-3(2)$ & $8.222 \mathrm{E}-4(2)$ & $4.220 \mathrm{E}-4(3)$ & $2.171 \mathrm{E}-4(3)$ & $1.102 \mathrm{E}-4(4)$ & $5.553 \mathrm{E}-5(4)$ \\
& 0.826 & 0.962 & 0.958 & 0.978 & 0.989 & \\
\hline$d_{2}^{N, M}$ & $1.458 \mathrm{E}-3$ & $8.222 \mathrm{E}-4$ & $4.220 \mathrm{E}-4$ & $2.171 \mathrm{E}-4$ & $1.102 \mathrm{E}-4$ & $5.553 \mathrm{E}-5$ \\
$p_{2}^{N}, M$ & 0.826 & 0.962 & 0.958 & 0.978 & 0.989 & \\
& & & & & & \\
\hline
\end{tabular}

6. P.A. Farrell, A.F. Hegarty, J.J.H. Miller, E. O'Riordan, G.I. Shishkin, Robust Computational Techniques for Boundary Layers, Applied Mathematics, 16. Chapman and Hall/CRC, 2000.

7. F.J. Gaspar, C. Clavero, F. Lisbona, Multigrid methods and finite difference schemes for 2D singularly perturbed problems. Numerical analysis and its applications (Rousse, 2000), 316-324, Lecture Notes in Comput. Sci., 1988, Springer, Berlin, 2001.

8. F.J. Gaspar, C. Clavero, F. Lisbona, Some numerical experiments with multigrid methods on Shishkin meshes, J. Comput. Appl. Math., 138 (2002) 21-35.

9. J.L. Gracia, F. Lisbona, A uniformly convergent scheme for a system of reaction-diffusion equations, J. Comp. Appl. Math. 206 (2007) 1-16.

10. J.L. Gracia, F. Lisbona, E. O'Riordan, A coupled system of singularly perturbed parabolic reaction-diffusion equations, Adv. Comput. Math. 32 (2010) 43-61.

11. J.L. Gracia, N. Madden, T.A. Nhan, Applying a patched mesh method to efficiently solve a singularly perturbed reaction-diffusion problem. To appear in Modeling, Simulation and Optimization of Complex Processes, Springer (proceedings of the 6th International Conference on High Performance Scientific Computing, Vietnan 2015).

12. R.B. Kellogg, T. Linss, M. Stynes, A finite difference method on layer-adapted meshes for an elliptic reaction-diffusion system in two dimensions, Math. Comput. 774 (2008) 2085-2096.

13. R.B. Kellogg, N. Madden, M. Stynes, A parameter robust numerical method for a system of reaction-diffusion equations in two dimensions, Numer. Methods Partial Differential Equations 24 (2007) 312-334.

14. T. Linss, M. Stynes, Numerical solution of systems of singularly perturbed differential equations, Comput. Methods Appl. Math. 9 (2009) 165-191.

15. S. MacLachlan, N. Madden, Robust solution of singularly perturbed problems using multigrid methods, SIAM J. Sci. Comput., 35 (2013) A2225-A2254.

16. N. Madden, M. Stynes, A uniformly convergent numerical method for a coupled system of two singularly perturbed linear reaction-diffusion problems, IMA J. Numer. Anal. 23 (2003) 627-644.

17. S. Matthews, E. O'Riordan, G.I. Shishkin, A numerical method for a system of singularly perturbed reaction-diffusion equations, J. Comput. Appl. Math. 145 (2002) 151-166. 
Table 7 Example 2: Maximum and uniform two-mesh differences and their orders of convergence for the component $u_{3}$. Maximum number of iterations for all the times levels in brackets

\begin{tabular}{|c||c|c|c|c|c|c|}
\hline \multicolumn{1}{|c|}{} & $\mathrm{N}=16$ & $\mathrm{~N}=32$ & $\mathrm{~N}=64$ & $\mathrm{~N}=128$ & $\mathrm{~N}=256$ & $\mathrm{~N}=512$ \\
\hline & $\mathrm{M}=8$ & $\mathrm{M}=16$ & $\mathrm{M}=32$ & $\mathrm{M}=64$ & $\mathrm{M}=128$ & $\mathrm{M}=256$ \\
\hline \hline$\varepsilon^{2}=1$ & $6.359 \mathrm{E}-5(6)$ & $3.551 \mathrm{E}-5(7)$ & $2.098 \mathrm{E}-5(8)$ & $1.135 \mathrm{E}-5(8)$ & $5.896 \mathrm{E}-6(8)$ & $3.006 \mathrm{E}-6(8)$ \\
& 0.841 & 0.759 & 0.887 & 0.945 & 0.972 & \\
\hline$\varepsilon^{2}=10^{-1}$ & $1.521 \mathrm{E}-3(6)$ & $8.523 \mathrm{E}-4(7)$ & $4.539 \mathrm{E}-4(7)$ & $2.346 \mathrm{E}-4(7)$ & $1.192 \mathrm{E}-4(7)$ & $6.009 \mathrm{E}-5(7)$ \\
& 0.835 & 0.909 & 0.952 & 0.976 & 0.988 & \\
\hline$\varepsilon^{2}=10^{-2}$ & $6.669 \mathrm{E}-3(4)$ & $3.533 \mathrm{E}-3(5)$ & $1.807 \mathrm{E}-3(5)$ & $9.133 \mathrm{E}-4(6)$ & $4.589 \mathrm{E}-4(6)$ & $2.301 \mathrm{E}-4(7)$ \\
& 0.917 & 0.967 & 0.984 & 0.993 & 0.996 & \\
\hline$\varepsilon^{2}=10^{-3}$ & $9.099 \mathrm{E}-3(3)$ & $4.645 \mathrm{E}-3(3)$ & $2.352 \mathrm{E}-3(3)$ & $1.184 \mathrm{E}-3(4)$ & $5.942 \mathrm{E}-4(5)$ & $2.976 \mathrm{E}-4(5)$ \\
& 0.970 & 0.982 & 0.990 & 0.995 & 0.998 & \\
\hline$\varepsilon^{2}=10^{-4}$ & $9.073 \mathrm{E}-3(2)$ & $4.873 \mathrm{E}-3(3)$ & $2.461 \mathrm{E}-3(3)$ & $1.236 \mathrm{E}-3(4)$ & $6.197 \mathrm{E}-4(5)$ & $3.103 \mathrm{E}-4(5)$ \\
& 0.897 & 0.986 & 0.993 & 0.996 & 0.998 & \\
\hline$\varepsilon^{2}=10^{-5}$ & $9.627 \mathrm{E}-3(2)$ & $4.909 \mathrm{E}-3(3)$ & $2.477 \mathrm{E}-3(3)$ & $1.248 \mathrm{E}-3(4)$ & $6.254 \mathrm{E}-4(4)$ & $3.130 \mathrm{E}-4(5)$ \\
& 0.972 & 0.987 & 0.989 & 0.997 & 0.998 & \\
\hline$\varepsilon^{2}=10^{-6}$ & $9.702 \mathrm{E}-3(2)$ & $4.941 \mathrm{E}-3(3)$ & $2.492 \mathrm{E}-3(3)$ & $1.251 \mathrm{E}-3(4)$ & $6.267 \mathrm{E}-4(4)$ & $3.136 \mathrm{E}-4(4)$ \\
& 0.974 & 0.987 & 0.994 & 0.997 & 0.999 & \\
\hline$\varepsilon^{2}=10^{-7}$ & $9.707 \mathrm{E}-3(2)$ & $4.943 \mathrm{E}-3(3)$ & $2.493 \mathrm{E}-3(3)$ & $1.252 \mathrm{E}-3(4)$ & $6.267 \mathrm{E}-4(4)$ & $3.136 \mathrm{E}-4(4)$ \\
& 0.973 & 0.988 & 0.994 & 0.998 & 0.999 & \\
\hline$\varepsilon^{2}=10^{-8}$ & $9.706 \mathrm{E}-3(2)$ & $4.943 \mathrm{E}-3(3)$ & $2.493 \mathrm{E}-3(3)$ & $1.252 \mathrm{E}-3(4)$ & $6.267 \mathrm{E}-4(4)$ & $3.136 \mathrm{E}-4(4)$ \\
& 0.974 & 0.988 & 0.994 & 0.998 & 0.999 & \\
\hline$\varepsilon^{2}=10^{-9}$ & $9.705 \mathrm{E}-3(2)$ & $4.942 \mathrm{E}-3(3)$ & $2.492 \mathrm{E}-3(3)$ & $1.252 \mathrm{E}-3(4)$ & $6.267 \mathrm{E}-4(4)$ & $3.136 \mathrm{E}-4(4)$ \\
& 0.974 & 0.988 & 0.994 & 0.998 & 0.999 & \\
\hline$\varepsilon^{2}=10^{-10}$ & $9.705 \mathrm{E}-3(2)$ & $4.942 \mathrm{E}-3(3)$ & $2.492 \mathrm{E}-3(3)$ & $1.252 \mathrm{E}-3(4)$ & $6.267 \mathrm{E}-4(4)$ & $3.136 \mathrm{E}-4(4)$ \\
& 0.974 & 0.988 & 0.994 & 0.998 & 0.999 & \\
\hline$d_{3}^{N, M}$ & $9.707 \mathrm{E}-3$ & $4.943 \mathrm{E}-3$ & $2.493 \mathrm{E}-3$ & $1.252 \mathrm{E}-3$ & $6.267 \mathrm{E}-4$ & $3.136 \mathrm{E}-4$ \\
$p_{3}^{N, M}$ & 0.973 & 0.988 & 0.994 & 0.998 & 0.999 & \\
\hline
\end{tabular}

18. J.J.H. Miller, E. O'Riordan, G.I. Shishkin, Fitted numerical methods for singular perturbation problems, World Scientific, revised edition, 2012.

19. M.H. Protter, H.F.Weinberger, Maximum Principle in Differential Equations, PrenticeHall, Englewood Cliffs, NJ, 1967.

20. H.G. Roos, M. Stynes, L. Tobiska, Robust numerical methods for singularly perturbed differential equations, Springer Series in Computational Mathematics, Berlin, 2008.

21. G.I. Shishkin, Approximation of systems of singularly perurbed elliptic reactiondiffusion equations with two parameters, Comput. Math. Math. Phys. 47 (2007) 797-828.

22. G.I. Shishkin, L.P. Shishkina, Approximation of a system of singularly perturbed parabolic reaction-diffusion equations in a rectangle, Zh. Vychisl. Mat. Mat. Fiz. 48 (2008) 660-673 (in Russian); translation in Comput. Math. Math. Phys. 48 (2008) 627-640.

23. G.I. Shishkin, L.P. Shishkina, Difference methods for singular perturbation problems, Chapman \& Hall/CRC Press, Boca Raton, 2009.

24. L.P. Shishkina, G.I. Shishkin, Robust numerical method for a system of singularly perturbed parabolic reaction-diffusion equations on a rectangle, Math. Model. Anal. 13 (2008) $251-261$.

25. U. Trottenberg, C. W. Oosterlee, A. Schüller, Multigrid, Academic Press, Inc., San Diego, CA, 2001.

26. P.N. Vabishchevich, Additive operator-difference schemes. Splitting schemes, De Gruyter, Berlin, 2014. 